\title{
Utilization of Buildings' Foundations for a Seasonal Thermal Energy Storage Medium to Meet Space and Water Heat Demands
}

\author{
Ammar Alkhalidi $(\mathbb{D}$, Hamzah Al Khatba $(\mathbb{D}$, and Mohamad K. Khawaja \\ Energy Engineering Department, German Jordanian University, Amman 11180, Jordan \\ Correspondence should be addressed to Ammar Alkhalidi; ammar.alkhalidi@gju.edu.jo
}

Received 5 December 2020; Revised 16 February 2021; Accepted 24 February 2021; Published 19 March 2021

Academic Editor: Kumarasamy Sudhakar

Copyright (c) 2021 Ammar Alkhalidi et al. This is an open access article distributed under the Creative Commons Attribution License, which permits unrestricted use, distribution, and reproduction in any medium, provided the original work is properly cited.

\begin{abstract}
Seasonal thermal energy storage (STES) can be utilized to cover a portion or meet the whole space and water heat demands in residential and commercial buildings. With the scarcity of fuel resources, scientists have become aware of the importance of the utilization of thermal energy. An STES system can be charged using solar collectors to heat a storage medium when solar radiation is available. Solar irradiance is seasonal so this type of system can compensate for the shortage of energy in the winter by storing surplus solar energy in the summer. This study offers an innovative design of an STES system that takes advantage of the backfill space in a building's underground foundation to install the thermal storage medium on the excavated surface among the support pillars' base. To study the feasibility and the feasibility of such STES system, the design was simulated using the TRNSYS $^{\circledR}$ tool where the STES medium was charged by a solar thermal system. The chosen building type was a four-story hotel located in three cities each with its unique climate: Potsdam (Germany), Zarqa (Jordan), and Doha (Qatar). The results showed the coverage rate of the building's annual heat demand was $56 \%, 82 \%$, and $84 \%$, and the payback periods were $3.4,4.4$, and 29 years for Potsdam, Zarqa, and Doha, respectively. Zarqa is the most efficient and feasible for STES compared to the other two cities.
\end{abstract}

\section{Introduction}

Buildings are one of the biggest energy consumers with $32 \%$ of the total final energy consumption in the world according to the International Energy Agency. The fossil energy systems can be replaced by solar energy systems especially for locations with high annual solar radiation, which lead to prevent large greenhouse gas emissions and reduce the negative impact on the environment as well. Solar energy, while clean and renewable, is diurnal and seasonal in nature, hence, the importance of implementing techniques to store this energy for later use when solar radiation is low or entirely unavailable. Seasonal thermal energy storage (STES) is implemented widely by using different technologies. Depending on the STES medium, surplus thermal energy from the summer can be stored and then used in the winter at various scales ranging from single-family homes, hotels, districts, towns, or regions.

Humans have been searching for means to store energy; therefore, energy storage is considered an old practice. In ancient Greece and Romans times, architects used solar energy inside their buildings to heat water. They designed their bathhouses' openings to acquire solar heating to support their existing bath fire, thus reducing the fuel needed for water heating loads [1]. Native Americans inhabited caves that best utilize solar energy in winter and summer at the Grand Canyon of Arizona. The low azimuth angle of the sun in the winter provided heat while the shading of the natural cliff blocked the summers' high azimuth angle.

Nowadays, there is a continuous increase in energy demand globally. Climate change significantly affects cooling and heating loads as well as the annual energy demands of for a building [2]. Solar thermal energy could be stored for months and seasons solar thermal systems' efficiency, sustainability, and productivity can be improved by implementing an STES criteria.

Solar thermal energy can be stored by changing the internal energy of different materials in different phases. Materials that could be utilized are sensible, latent, and thermochemical as a medium of an STES. Furthermore, materials could 
be combined to achieve the required thermal properties. Due to the rising temperature of the thermal storage medium, the atoms and molecules of its materials vibrate faster and collide with each other to release the thermal energy. This allows the thermal energy to be stored as a change of the internal energy of the material in many forms. Sensible heat, latent heat, and thermochemical heat are forms of energy storage; a combination of these forms is also possible for storage [3].

The sun provides enough energy to meet global demand; however, many variables affect the accumulated energy from the sun. Therefore, some sort of energy storage system must be introduced to maximize the benefit of solar energy. Solar thermal systems use heat collectors to capture solar energy to be utilized according to the demand load. Energy can be stored for short-term and extended periods (seasonal) according to the storage system's size. Seasonal energy storage is evaluated to be 100 to 1000 times larger in capacity than short-term storage size [4].

A reference approach of STES was designed, modeled, and simulated at four buildings in different cities under various climatic zones in Europe (Stockholm, Zurich, Barcelona, and Madrid). A solar thermal system was linked with the STES to discharge the thermal energy to the buildings' heating applications. The simulation was implemented by using TRNSYS $^{\circledR}$ software. The authors of the study found that a STES with $1 \mathrm{~m}^{3}$ volume that was charged by $20 \mathrm{~m}^{2}$ flat plate collectors and supported by $10 \mathrm{~kW}$ auxiliary heater can cover the buildings' annual heating demand [5].

The performance of underground fabricated sand bed STES in six different typical single-family homes' models in Richmond, Virginia, USA, was tested by using TRNSYS $^{\circledR}$, where the simulation was performed to calculate the stored thermal energy in $15 \mathrm{~m}^{3}$ STES that gained from flat plate solar thermal collectors to cover the home's space heat demand. As a result, the overall system efficiency ranged from 50 to $70 \%$ compared with total useful solar energy. And the maximum temperature of the STES reached in the 5 -year simulation was $96.1^{\circ} \mathrm{C}$ [6], while other researchers studied the performance of STES under the same simulation's parameters for a five-story student housing complex at Virginia Commonwealth University. The simulation was performed by using TRNSYS ${ }^{\circledR}$ on 15 thermal energy storage locations to make optimization to choose the most efficient STES system. As a result, the STES can cover more than $91 \%$ of the building's space heat demand after the fifth year of its operation [7].

Multiple authors investigated the use of solid materials as a sensible heat storage medium. A study of storing of the thermal solar energy in the soil in the summer season in Al-kreaat quarter in Baghdad used the quasi-threedimensional model and finite line source model in their computations. The results found that $38 \%$ of the total collected energy can be stored in the soil which indicated that the amount of stored energy depends on the borehole length [8]. An investigation on covering the heat demand of four buildings within a complex by using STES placed in the ground. The capacity of STES was $5,700 \mathrm{~m}^{3}$ that was charged by a solar thermal system with collectors' area $4,700 \mathrm{~m}^{2}$. Several scenarios were analyzed based on the buildings' heat demand to optimize the best size of the STES, and as a result, the optimized STES could give around 53\% solar fraction factor where that could decrease heat consumption by $22-100 \%$ throughout the year [9].

A TRNSYS ${ }^{\circledR}$ simulation was performed on a typical STES system for a typical $120 \mathrm{~m}^{2}$ building in Thessaloniki, Greece. The simulation performed to calculate the covered building's space and water heat demand by $36 \mathrm{~m}^{3}$ hot water STES. The operation of the simulated STES system was examined for two years. As a result, the hot water STES covered more than $52.3 \%$ of the building's heat demand, and the maximum temperature of the STES reached in the second year simulation was in the range $84-90^{\circ} \mathrm{C}[10]$.

Sand-bed thermal energy storage (TES) system experiment was conducted in a region with an extended freezing period at a two-story house located in Palmer, Alaska, using TRANSYS ${ }^{\circledR}$ simulation, and the simulated temperature of the sand-bed was compared to the measured one with a relative error of $15 \%$. The results indicate that such types of solar thermal storage systems are viable options for very cold climates [11]. Conversely, in the United Arab Emirates (UAE), a study demonstrated that the desert sand at UAE could be used in concentrated solar power (CSP) facilities to store thermal energy up to $1000^{\circ} \mathrm{C}$. The research project, Sand Stock, used sand particles as the heat collector, heat transfer, and TES media. The study concluded that desert sand can be used not only as a TES material but also as a direct solar absorber under concentrated solar flux [12].

The feasibility of STES using sensible, latent, and thermochemical heat storage technologies through a residential sector in eight cities in the United Kingdom (UK) was investigated, and a calculation modeling framework was used to estimate the critical solar collector areas and the required capacity of a TES [13].

In the case of using solid material as a medium of STES, a study examined the performance of a novel combined receiver storage system for beam down solar concentrator and tested different mixing ratios of sand and basalt to be used as the thermal storage medium. The finite element heat transfer model was used to solve the unsteady governing equations for the system. Accordingly, the achieved results showed that the utilization factor is in the range of $0.53-$ 0.73 depending on the conductive rods configuration and the sand-basalt mixture ratio. Furthermore, the utilization factor increases by increasing the basalt percentage [14]. Others experimented with the utilization of the basalt stone as a material in sensible heat storage and found that it has a high energy density of $4.2 \times 103 \mathrm{~kJ} \mathrm{~m}^{-3} \mathrm{~K}^{-1}$ [15].

The performance of underground water STES in a cold climatic zone in Ottawa, Canada, was tested where the storage volume was $36 \mathrm{~m}^{3}$ and charged by $41.6 \mathrm{~m}^{2}$ evacuated tube collectors for covering the heat demand of a single-family home. The simulation tools used were TRNSYS ${ }^{\circledR}$ and ESP$\mathrm{r}$; as a result, the covered home's heat demand was in the range of $87-98 \%$ using this system [16].

A study assessed using STES instead of using an air-source heat pump to cover the space heat demand of a $240 \mathrm{~m}^{2}$ house in Hangzhou, China. A TRNSYS simulation was performed to develop and optimize short-term solar STES to reach the 
lowest annual cost over 20 years. The electricity demand reduction was $74 \%$ by the optimized STES [17].

All researches emphasized that there is an urgent need to develop and apply smart and flexible heat systems by integrating thermal energy storage. In this case, thermal energy storage can provide high-demand response, which will need smart operating system and control techniques.

This study investigates a novel STES systems by utilizing silica sand, basalt stone, and copper mesh, in placed of the backfilled area in the foundations' layer underneath a building. Using the available spaces for the underground STES could reduce the cost of the required excavation and also providing a method for taking advantage of an otherwise underutilized area. The STES system will be simulated in three different climatic zones to assess its performance based on the variations in the climatic features of the selected locations: (i) Zarqa-Jordan, (ii) Doha-Qatar, and (iii) PotsdamGermany. The authors chose the sensible STES type instead of latent/thermochemical because it is the safest, the most common, the simplest, and the cheapest one [1].

This research investigated the possibility and the feasibility of using such STES to meet space and water heat demands of a hotel building in the three climatic zones using TRNSYS $^{\circledR}$ simulation software.

\section{Methodology}

The heat demand for space heating (SH) and domestic hot water (DHW) of the buildings will be calculated utilizing the degree days method. A proper solid material will be utilized in a sensible STES to cover the building's heat demand. This study investigates the thermal energy application of an STES system under a proper boundary and initial conditions that will be discussed in detail in the next sections. Investigation of the reliability of the designed STES system relied on mainly three energy pillars: energy storage, renewable production, and STES system sustainability [18]. The authors represented the three energy pillars in the results. Thermal energy transfers throughout the whole system are illustrated in Figure 1 as a simple schematic diagram. A simulation study will be performed for the STES system in the selected locations by using TRNSYS $^{\circledR}$ software. An economical evaluation for capital and operation cost of the STES system compared with the heat demand electricity cost will be done in the nest sections. Finally, the simulation and the economical evaluation results will be analyzed to assess the STES performance and feasibility in the selected locations. The steps and procedures to be followed are presented in a chart shown in Figure 2.

\section{Design and Simulation}

Three different climatic zones were selected to test the performance of the STES and its feasibility for different weather conditions, Zarqa in Jordan, Doha in Qatar, and Potsdam in Germany. The climatic and solar properties for the three cities are shown in Table 1 according to the National Climatic Data Center [19] and Photovoltaic Geographical Information System [20], based on the different climate features, including temperature, humidity, and cloud cover. The

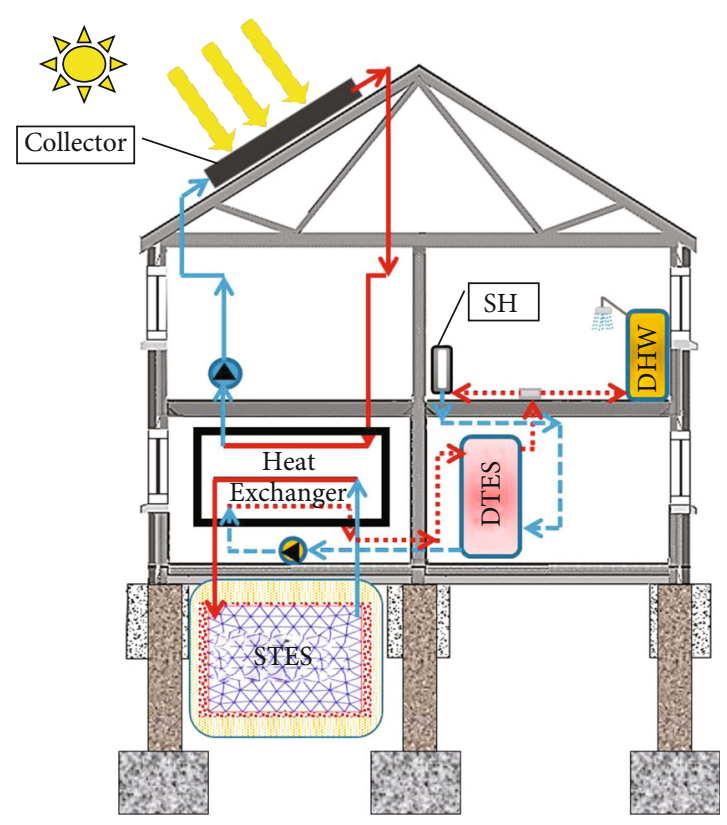

FIGURE 1: Seasonal thermal energy storage and solar combisystem schematic diagram in a building. *STES: seasonal thermal energy storage; DTES: diurnal thermal energy storage; $\mathrm{SH}$ : space heating; DHW: domestic hot water.

authors will assess the best performance of the STES that will be relevant to the best solar energy features for one of the selected locations. Jordan is characterized by having available solar energy along with more than 300 sunny days/year, where it is one of the sun-belt states and most of its area is exposed to a very high solar irradiance [21].

The annual incident solar irradiance is 2337,2191 , and $1241 \mathrm{kWh} \mathrm{m}^{-2}$ for Zarqa, Doha, and Potsdam, respectively, according to Global Solar Atlas Data [22].

3.1. Architectural Design of the Building. The four-story building, hotel with floor area $400 \mathrm{~m}^{2}$, was chosen for this study's design and simulation. The building was designed with the same dimensions and orientation (north orientation) in the three cities but with different insulation materials due to the different weather conditions. The hotel's occupation capacity is 80 persons including the staff, while the capacity of each bedroom hosts two persons. The hotel building was drawn using SketchUp ${ }^{\circledR}$ in a three-dimensional view as shown in Figure 3(a) and a two-dimensional floorplan for the ground floor and the one above it as shown in Figure 3(b). Three different buildings' envelope constructions were designed following the codes as, listed in Table 2, to reduce the heat loss/gain due to the different levels of weather conditions. The authors used Polyurethane insulation panels between outside stone and internal concrete hollow block as a wall assembly in different thicknesses based on the climatic features of each selected location [23].

\subsection{Hotel's Heat Demand}

3.2.1. Hotel's Space Heating Load. The authors proposed a novel methodology for calculating hotel's space heating 


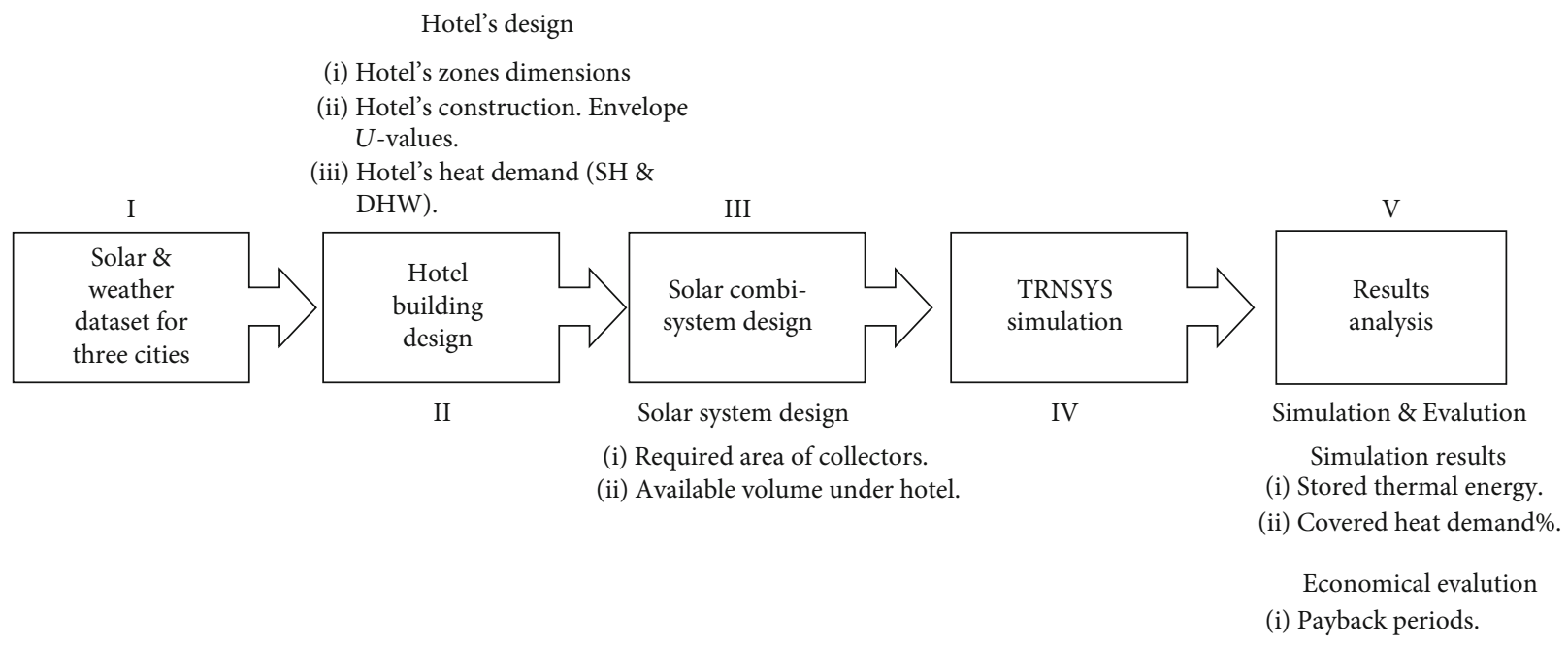

Figure 2: Block diagram of the research methodology's steps.

TABLE 1: Climatic properties for the three locations $[19,20]$.

\begin{tabular}{lccccccccccc}
\hline City & $\begin{array}{c}\text { Climatic } \\
\text { zone }\end{array}$ & Lat. & Long. & Alt. & $\begin{array}{c}T_{\text {avg }} \\
\left({ }^{\circ} \mathrm{C}\right)\end{array}$ & $\begin{array}{c}T_{\min } \\
\left({ }^{\circ} \mathrm{C}\right)\end{array}$ & $\begin{array}{c}T_{\max } \\
\left({ }^{\circ} \mathrm{C}\right)\end{array}$ & $I_{\mathrm{G}}\left(\mathrm{kWh} \cdot \mathrm{m}^{-2} \mathrm{a}^{-1}\right)$ & $I_{\mathrm{B}}\left(\mathrm{kWh} \mathrm{m}^{-2} \mathrm{a}^{-1}\right)$ & $I_{\mathrm{D}}\left(\mathrm{kWh} \mathrm{m}^{-2} \mathrm{a}^{-1}\right)$ & $\mathrm{HDD}(\mathrm{K} \mathrm{d})$ \\
\hline Zarqa & Semiarid & 32.3 & 36.2 & 682.8 & 18.33 & 1 & 36 & 2,109 & $1,494.7$ & 615.12 \\
Doha & Desert & 25.3 & 51.6 & 10.7 & 28.9 & 12 & 45 & 2,173 & $1,473.3$ & 699.4 \\
Potsdam & Humid temp. & 52.4 & 13.1 & 81 & 10.5 & -3.1 & 25.6 & 1,110 & 542.6 & 567.6 & $3,097.3$ \\
\hline
\end{tabular}

$I_{\mathrm{B}}$ : beam incident irradiation; $I_{\mathrm{D}}$ : diffuse incident irradiation; $I_{\mathrm{G}}$ : global (total) incident irradiation; HDD: heating degree days; $T_{\text {avg: }}$ average air temperature; $T_{\min }:$ minimum air temperature; $T_{\max }:$ maximum air temperature.

demand. Space heating $(\mathrm{SH})$ loads of the three buildings were calculated based on the degree days method [25]. The designation of heating degree days for the three different climatic zones provides a tempo-spatial map of heating demand. The knowledge of total hotel's space heating demand was used to identify the accumulated heat demand curve, appropriate for seasonal thermal energy storage system modelling.

The conduction and infiltration loads of the hotel buildings were calculated using equations ((1)-(3)) with $21^{\circ} \mathrm{C}$ indoor design temperature.

$$
\begin{gathered}
Q_{\mathrm{T}}=Q_{\mathrm{c}}+Q_{\mathrm{i}}, \\
Q_{\mathrm{C}}=\frac{24}{1000} U \times A \times \mathrm{HDD}, \\
Q_{\mathrm{i}}=\frac{24}{1000} \times \frac{\rho c_{\mathrm{p}} V}{3600} \times \mathrm{HDD},
\end{gathered}
$$

where $Q_{c}$ is the heat gain/loss due to conduction through walls, windows, and roof $(\mathrm{kWh}) ; Q_{\mathrm{i}}$ is the heat gain/loss due to infiltration (kWh); $U$ is the overall heat transfer coefficient $\left(\mathrm{W} \mathrm{m}^{-2} \cdot \mathrm{K}^{-1}\right) ; A$ is the surface area for walls, windows, or roofs $\left(\mathrm{m}^{2}\right)$; HDD is the heating degree days ( $\mathrm{K}$ day); $\rho$ is the density of air $\left(1.225 \mathrm{~kg} \mathrm{~m}^{-3}\right) ; C_{\mathrm{p}}$ is the specific heat of air $\left(1000 \mathrm{~J} \mathrm{~kg}^{-1} \mathrm{~K}^{-1}\right) ; V$ is the volume changed per hour based on the Air Change Method $\left(\mathrm{m}^{3} \mathrm{~h}^{-1}\right)$.
Two schedules of the hotel's internal load that generated by occupancy and electrical equipment were estimated by the authors to calculate the amount of heat gain.

The resulting annual space heating load is shown in Figure 4. It can be noticed that the annual space heating load for Potsdam was the highest at $101 \mathrm{kWh} \mathrm{m}^{-2}$ year $^{-1}$, which is comparable to the $100 \mathrm{kWh} \mathrm{m}^{-2}$ year ${ }^{-1}$ for the hotel sector in Germany [26]. On the other hand, the annual space heating load for Zarqa was $57 \mathrm{kWh} \mathrm{m}^{-2}$ year ${ }^{-1}$; this result is a bit lower than what was previously recorded at around $95 \mathrm{kWh} \mathrm{m}^{-2}$ year $^{-1}$ [25]. This could be attributed to the fact that this study used a building envelope's construction with $U$ values lower by half than the one that was used in [25]. Finally, the annual space heating load for Doha city was the lowest one at $14 \mathrm{kWh} \mathrm{m}^{-2}$ year $^{-1}$ due to its warm climate throughout the year. This result is comparable to $15 \mathrm{kWh} \mathrm{m}^{-2}$ year $^{-1}$ previously recorded for Doha [27].

3.2.2. Hotel's Domestic Hot Water (DHW) Load. It was assumed that the percentage of the annual occupation of the hotel is $60 \%$ (around 45 residents). The daily DHW consumed per person was estimated to be equal to 30 liters person $^{-1}$ day $^{-1}$ at a set temperature for the hot water at $55^{\circ} \mathrm{C}$ according to the Standard Assessment Procedure (SAP) [28]. And the cold water temperatures were generated from NOAA website for the three cities, respectively [19]. The hotel's DHW load was calculated based on equations (4)-(5) [29].

$$
Q_{w}=M_{d} \times C_{\text {water }} \times \Delta T \text {, }
$$




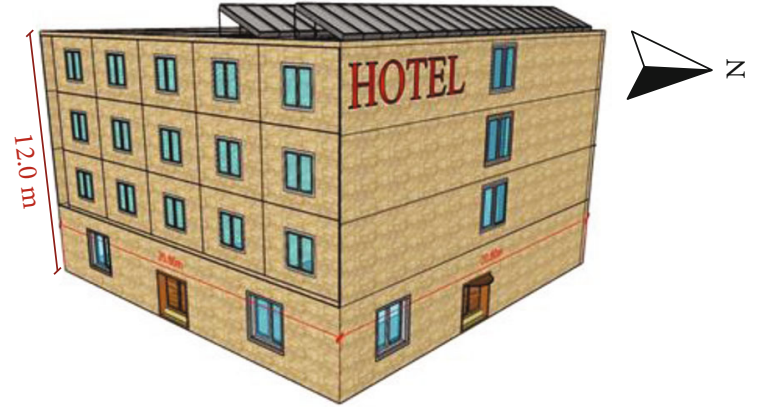

(a)

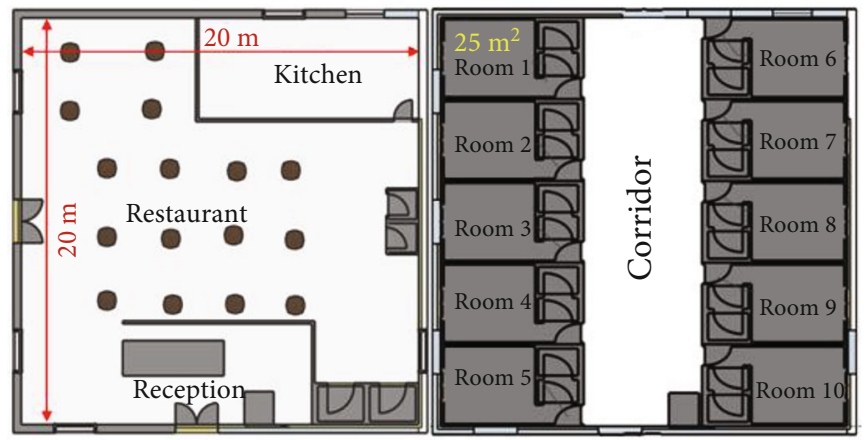

(b)

Figure 3: (a) 3D sketch of the hotel and (b) 2D cross-section for ground and first floor areas.

TABLE 2: Building envelope's construction specifications $[23,24]$.

\begin{tabular}{lccccccc}
\hline \multirow{2}{*}{ Component } & \multirow{2}{*}{ Area $\left(\mathrm{m}^{2}\right)$} & \multicolumn{3}{c}{ Construction thickness $(\mathrm{m})$} & \multicolumn{3}{c}{ Construction $U$ value $\left(\mathrm{W} \mathrm{m}^{-2} \mathrm{~K}^{-1}\right)$} \\
& & Zarqa & Doha & Potsdam & Zarqa & \multicolumn{2}{c}{ Doha } \\
\hline Floor & 400 & 0.37 & 0.445 & 0.285 & 0.24 & 0.57 & 0.5 \\
External wall & $240 \mathrm{x} 4$ & 0.39 & 0.468 & 0.288 & 0.24 & 0.57 \\
Roof & 400 & 0.23 & 0.335 & 0.12 & 0.24 & 0.44 & 0.5 \\
Internal walls & 1,223 & 0.2 & 0.2 & 0.2 & 0.962 & 0.962 \\
Doors & 80 & 0.15 & 0.15 & 0.15 & 2.7 & 3 \\
Windows & 125 & 0.3 & 0.3 & 0.2 & 3.1 & 0.92 \\
\hline
\end{tabular}

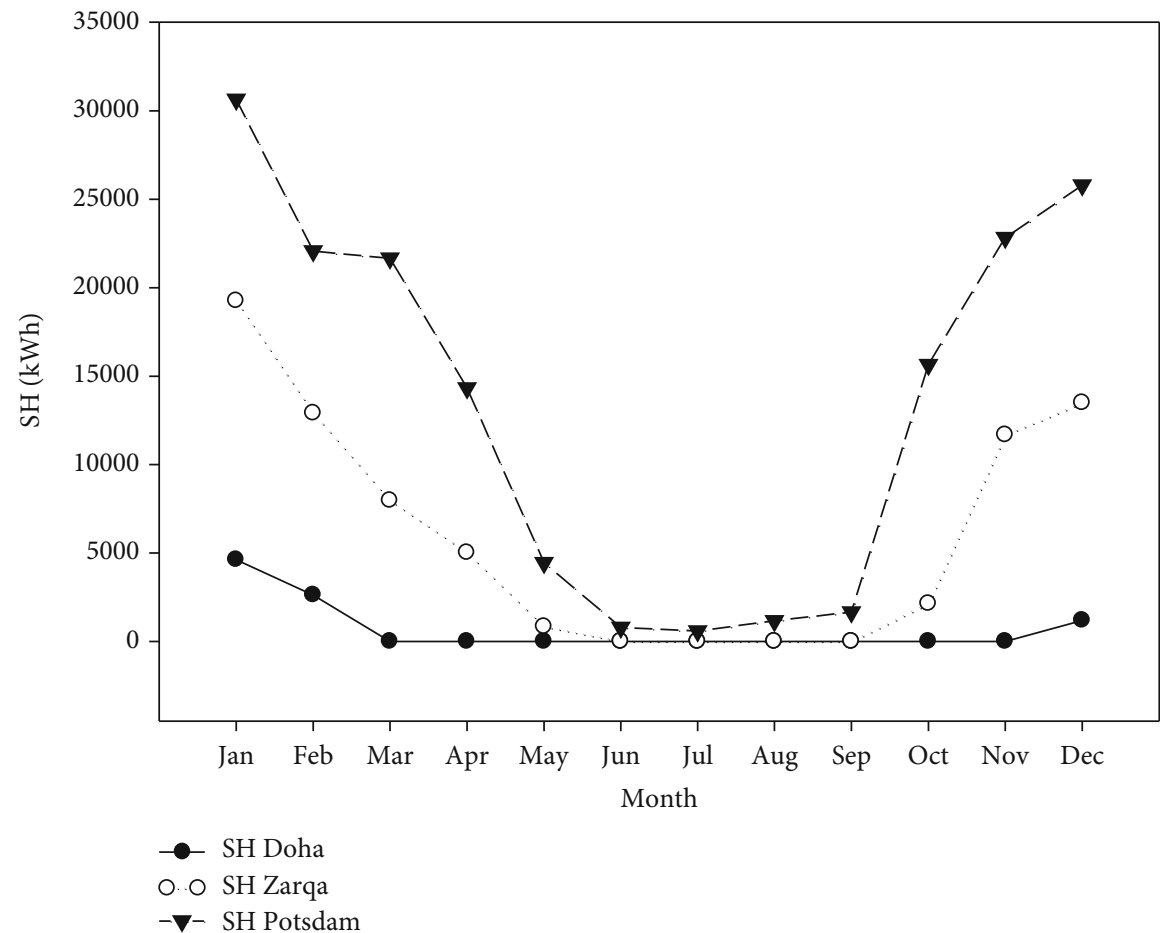

FIGURE 4: Monthly space heating loads for the three buildings (kWh) in the three selected cities. 


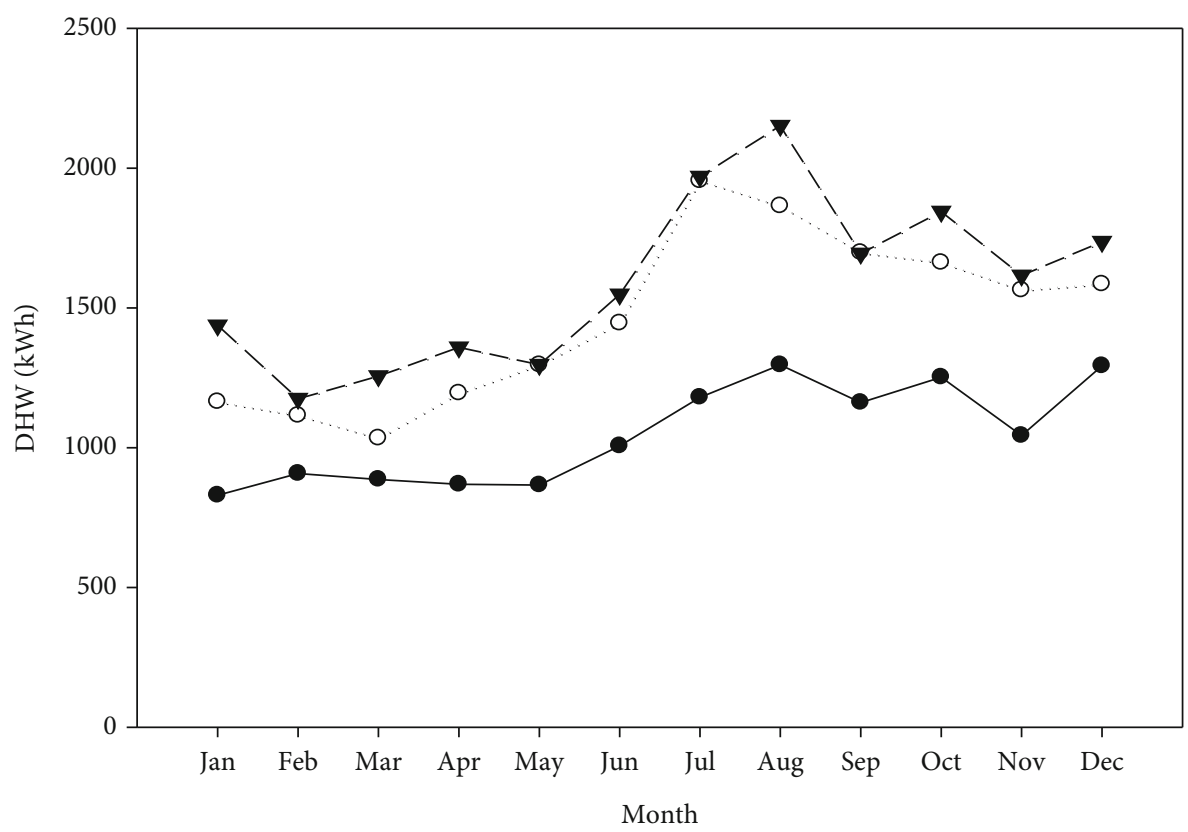

$\rightarrow$ DHW Doha

O. O DHW Zarqa

$-\boldsymbol{\nabla}$ - DHW Potsdam

(a)

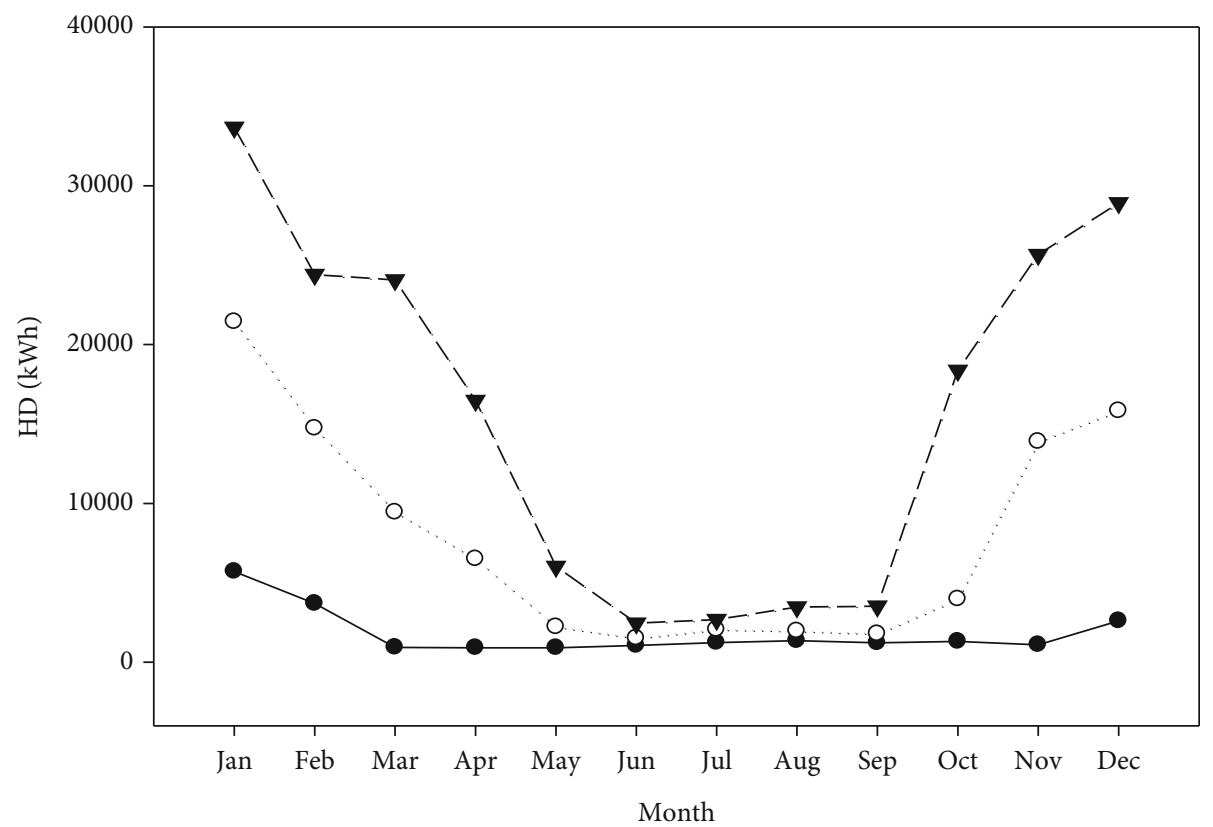

- HD Doha

O.. HD Zarqa

- - HD Potsdam

(b)

FIGURE 5: (a) Monthly DHW load for the three buildings (kWh) and (b) monthly total heating demand for the three buildings (kWh). 
TABLE 3: The technical details of the used solar thermal collector (CPC 18) [33].

\begin{tabular}{lccccccc}
\hline $\begin{array}{l}\text { Type of } \\
\text { collector }\end{array}$ & $\begin{array}{c}\text { Dimensions } \\
(\mathrm{m})\end{array}$ & $\begin{array}{c}\text { Number } \\
\text { of tubes }\end{array}$ & $\begin{array}{c}\text { Stationary } \\
\text { temperature }\left({ }^{\circ} \mathrm{C}\right)\end{array}$ & $\begin{array}{c}\text { Peak output per } \\
\text { module }\left(W_{\text {peak }}\right)\end{array}$ & $\begin{array}{c}\text { Conversion } \\
\text { factor } \eta_{0}\end{array}$ & $\begin{array}{c}\text { Thermal } \\
\text { conductivity } a_{1} \\
\mathrm{~W} /\left(\mathrm{m}^{2} \mathrm{~K}\right)\end{array}$ & $\begin{array}{c}\text { Thermal } \\
\text { conductivity } a_{2} \\
\mathrm{~W} /\left(\mathrm{m}^{2} \mathrm{~K}\right)\end{array}$ \\
\hline CPC 18 & $1.6 * 2.1$ & 18 & 249 & 2039 & 0.713 & 0.974 & 0.005 \\
\hline
\end{tabular}

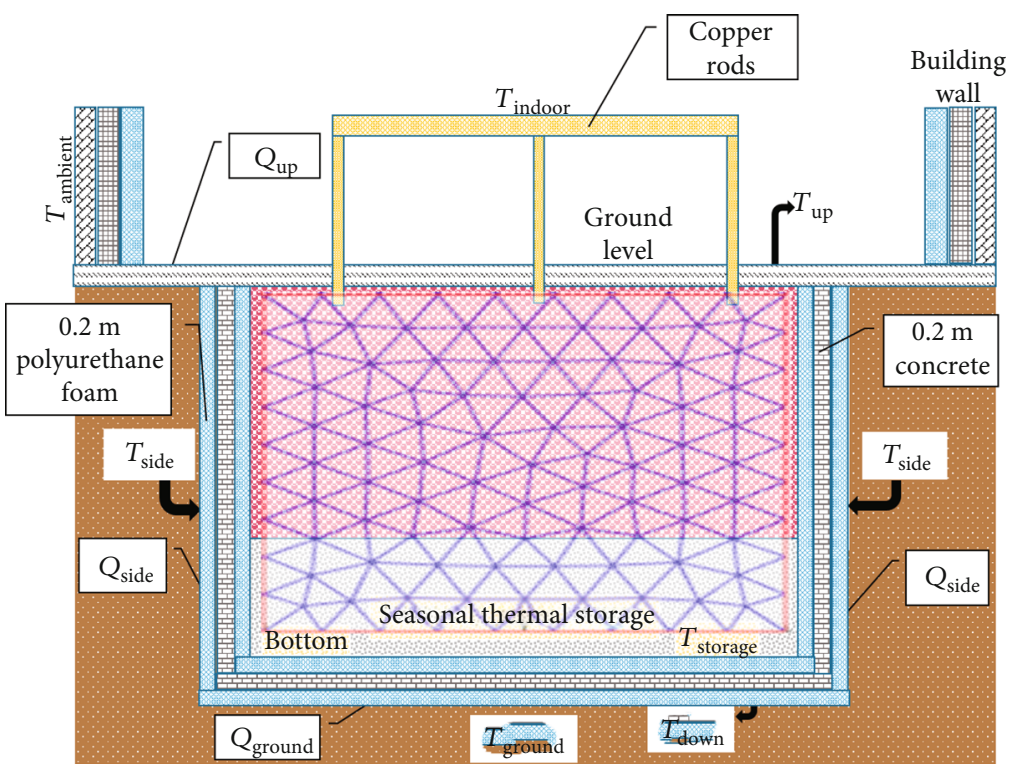

FIGURE 6: STES environmental variable diagram. ${ }^{*} T_{\text {ground }}$ : ground temperature; $T_{\text {side }}$ : STES surface temperature; $T_{\text {down }}:$ STES bottom temperature; $T_{\text {storage }}$ : STES temperature; $T_{\text {up }}$ : STES upper surface temperature; $T_{\text {indoor }}$ : hotel's indoor-air temperature. Temperature was measured by ${ }^{\circ} \mathrm{C}$; all $Q$ symbols are illustrating the heat loss according to their relevant temperatures.

$$
M_{d}=v_{d} \times \rho_{\text {water }},
$$

where $Q_{w}$ is the required energy for DHW load (kWh), $M_{d}$ is the volume of daily consumed hot water (liter day $\left.{ }^{-1}\right), C_{\text {water }}$ is the specific heat capacity of water $\left(1.16 \mathrm{kWh} \mathrm{m}^{-3} \mathrm{~K}^{-1}\right), \Delta T$ is the temperature difference between cold and hot water $(\mathrm{K})$, and $\rho_{\text {water }}$ is the density of water $\left(0.988 \mathrm{~kg} \mathrm{~m}^{-3}\right)$.

The resulting annual DHW load is shown in Figure 5(a); it is observed that it varies depending on the climatic zone, whereas the annual DHW load of Zarqa was $17,583 \mathrm{kWh}$ year $^{-1}$, the lowest annual DHW load was for Doha at $12,597 \mathrm{kWh} \mathrm{year}^{-1}$, and the highest load was that of Potsdam at $19,095 \mathrm{kWh}$ year $^{-1}$. All DHW loads are comparable to previously recorded results [29]. Consequently, the resulting total annual heating demand of the three cities is shown below in Figure 5(b).

\subsection{Solar Thermal Combisystem}

3.3.1. Solar Thermal Collector. Solar thermal collectors are the main source of the thermal energy that will supply to the building's thermal applications to cover its heat demand. The solar thermal collectors charge the STES for storing the thermal energy from the summer season to be used in the winter season. Such systems that consist of solar thermal collectors charging DHW and space heating $(\mathrm{SH})$ applications is called a solar thermal combisystem.
TABLE 4: STES medium's material thermal specifications [15, 42, 43].

\begin{tabular}{lcccc}
\hline Material & $\begin{array}{c}\text { Specific } \\
\text { heat }(\mathrm{kJ} \\
\left.\mathrm{kg}^{-1} \mathrm{~K}^{-1}\right)\end{array}$ & $\begin{array}{c}\text { Density } \\
\left(\mathrm{kg} \mathrm{m}^{-3}\right)\end{array}$ & $\begin{array}{c}\text { Thermal } \\
\text { conductivity } \\
\left(\mathrm{W} \mathrm{m}^{-1} \mathrm{~K}^{-1}\right)\end{array}$ & $\begin{array}{c}\text { Energy } \\
\text { Density } \\
\left(\mathrm{kJ} \mathrm{m}^{-3} \mathrm{~K}^{-1}\right)\end{array}$ \\
\hline $\begin{array}{l}\text { Silica sand } \\
\left(\mathrm{SiO}_{2}\right)\end{array}$ & 0.73 & 2,650 & 1.5 & $2,000-2,500$ \\
$\begin{array}{l}\text { Basalt } \\
\text { stone }\end{array}$ & 0.84 & 2,400 & 3.5 & 4,200 \\
\begin{tabular}{l} 
Copper \\
\hline
\end{tabular} & 0.39 & 8,700 & 400 & 3,500 \\
\hline
\end{tabular}

Evacuated tube collectors are more efficient than flat plate collectors, and they have a longer life cycle with lower required maintenance $[30,31]$. The used solar thermal collectors in this study were the Compound Parabolic Collector (CPC 18) due to their high efficiency and sustainability. The collectors were oriented to the south direction, and the simulation was performed with different collector tilts due to the incident solar irradiance in the three cities. The required area of collectors for three locations was calculated using equation (6) [32], where the solar fraction was estimated by authors to equal 0.8 [33]. The compound parabolic collectors (CPC) are typical collectors that are able to collect both beam and diffuse 
TABLE 5: TRNSYS ${ }^{\circledR}$ simulation parameters.

\begin{tabular}{|c|c|c|c|}
\hline Main & Zarqa & Doha & Potsdam \\
\hline Length of simulation (years) & 5 & 5 & 5 \\
\hline Simulation start & June & June & June \\
\hline Building floor area $\left(\mathrm{m}^{2}\right)$ & 400 & 400 & 400 \\
\hline \multicolumn{4}{|l|}{ STES } \\
\hline STES volume $\left(\mathrm{m}^{3}\right)$ & 300 & 50 & 300 \\
\hline STES insulation thickness (m) & 0.4 & 0.4 & 0.4 \\
\hline STES $C_{\mathrm{p}}(\mathrm{kJ} / \mathrm{kg} \cdot \mathrm{K})$ & 0.77 & 0.77 & 0.77 \\
\hline STES initial temperature $\left({ }^{\circ} \mathrm{C}\right)$ & 21.5 & 28.9 & 12.73 \\
\hline \multicolumn{4}{|l|}{ Collector } \\
\hline Working fluid & Ethylene glycol & Ethylene glycol & Ethylene glycol \\
\hline Collector type & CPC 18 & CPC 18 & CPC 18 \\
\hline Collector area $\left(\mathrm{m}^{2}\right)$ & 135 & 60 & 250 \\
\hline Tilt angle & $28^{\circ}$ & $25^{\circ}$ & $32^{\circ}$ \\
\hline$T_{\text {boil }}$ collector $\left({ }^{\circ} \mathrm{C}\right)$ & 155 & 155 & 155 \\
\hline$T_{\text {protection }} \operatorname{STES}\left({ }^{\circ} \mathrm{C}\right)$ & 150 & 150 & 150 \\
\hline
\end{tabular}

${ }^{*} C_{\mathrm{p}}$ : specific heat; CPC: compound parabolic collector.

radiation [34]. The technical details of the used solar thermal collector are shown in Table 3.

$$
A_{\mathrm{c}}=\frac{\text { No.of days } \times \mathrm{Q}_{\text {water }} \times \text { solar fraction }}{\text { yearly solar irradince } \times \text { Avg system efficiency }} .
$$

Two working fluid were used to be circulated in two loops that cross the heat exchanger. Ethylene glycol has far superior heat transfer properties more than propylene glycol. Accordingly, the ethylene glycol was circulated in the primary loop between the collectors and the heat exchanger because it provides effective freeze protection as long as the proper antifreeze concentration is maintained. Ethylene glycol would be changed every 3-5 years because the antifreeze fluids degrade over time [35]. The circulated hot water will pass through the second loop driven by pump power, and a part of that circulated hot water will be stored temporarily in diurnal thermal energy storage (DTES) for daily usage. The working fluid loops were illustrated as shown in Figure 1. Consequently, the volume of the DTES was calculated by using equation (7) $[36]$.

$V_{\mathrm{st}}=\left[\left(\right.\right.$ number of beds $\times$ annual occupancy $\left.\left.\% \times \mathrm{HWD}_{\mathrm{p}}\right)+\mathrm{HWD}_{\mathrm{r}}\right] \times 1.2$,

where $\mathrm{HWD}_{\mathrm{p}}$ is the average hot water demand per person (liters) and $\mathrm{HWD}_{\mathrm{r}}$ is the average hot water demand for the hotels' kitchens (liters) and the annual occupancy is $60 \%$ for the three cities.

3.3.2. Solar Thermal Heat Exchanger. Transferring the thermal energy from the solar collectors' circulation to the STES needs an effective heat exchanger working on a liquid to solid transferring approach as shown in Figure 1. According to the heat atlas [37], the shell and tube heat exchanger was the best choice to use in this STES system. Shell and tube heat exchanger has high effectiveness due to its large available heat transfer area. It was assumed that the effectiveness of the used heat exchanger is up to $90 \%$.

3.4. Seasonal Thermal Energy Storage (STES). An STES system was designed to fit in the filler area above the foundations' layer underneath the building. STES medium was solid materials like silica sand and basalt stone to be utilized as sensible heat storage (SHS) combined with a copper mesh to promote the distribution and diffusion of heat throughout the STES as shown in Figure 6. The whole parameters that illustrated in Figure 6; they were inserted in the STES component's models in TRNSYS ${ }^{\circledR}$ simulation software to clarify the STES thermal variables and its boundary conditions.

Three types of solid materials were investigated in this research to be utilized in the STES for storing the produced thermal energy by the solar thermal system throughout the year. The first one is the basalt stone; basalt is a very hard and dark-colored stone that is formed by volcanic activity, and it is available in many countries $[38,39]$. The second type was silica sand; it is a mineral resource that can be used for different applications due to its good thermal properties and availability in both Europe and Jordan [40]. The third type was copper; a copper mesh was used to distribute the thermal energy within the STES and then to transfer it to the building's thermal applications through the heat exchanger when it is required. Copper is characterized by its high hardness and its high transmissivity of thermal energy due to its high melting point and its high resistance to corrosion [41]. The thermal specifications of the STES medium's materials are presented in Table 4.

The required area of the buildings' foundations in the three cities is dependent on the type of land and live and dead 


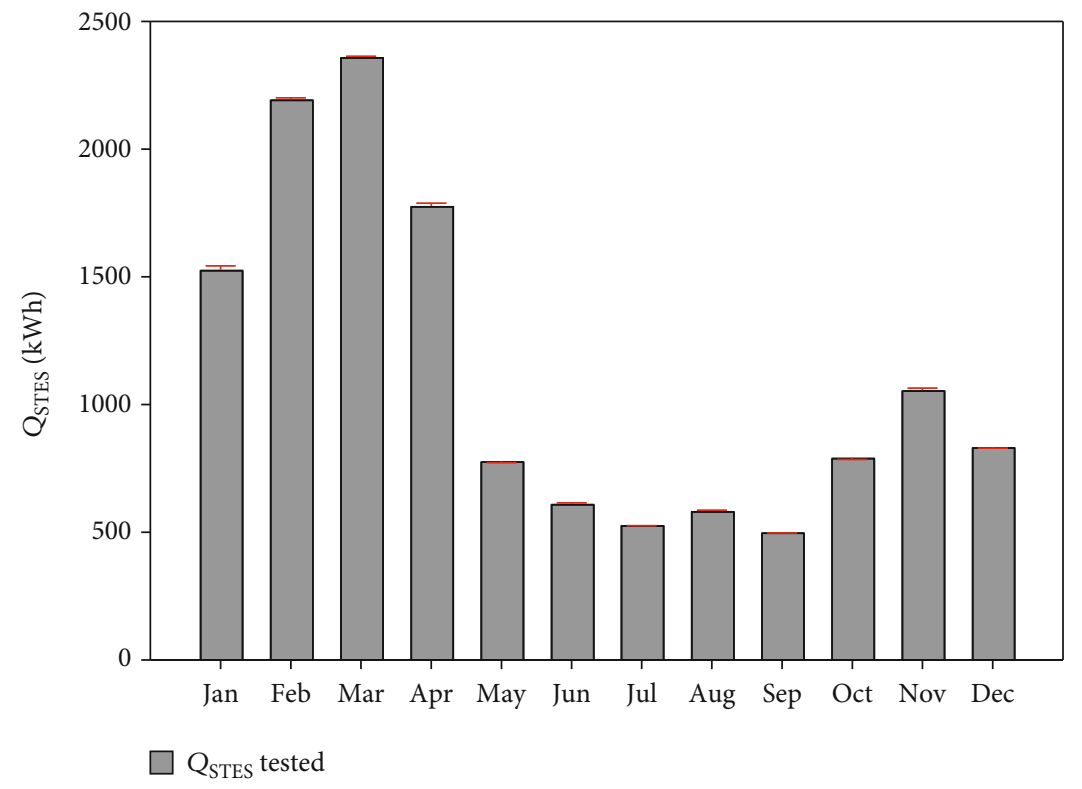

Figure 7: Comparison between $Q_{\text {STES }}$ of [16] and tested.

loads of the buildings. Based on that, the available area of the STES can be calculated by subtracting the required area of the building foundations from the overall building area. With the high variety of that characteristic of the three cities, it was assumed that the ratio of building's foundation area is $20 \%$ of the building's floor area depending on best practice records. Therefore, the available volume under the building is $300 \mathrm{~m}^{3}$.

The overall STES-specific heat was calculated using equation (8) and in accordance with the STES materials thermal specifications listed in Table 4 . The mass percentage was divided due to the highest specific heat $\left(C_{p}\right)$ of the STES materials. The percentage ratios are $65 \%$ of basalt stone, $30 \%$ of silica sand, and $5 \%$ of copper mesh.

$C_{\mathrm{p}, \mathrm{STES}}=\frac{m_{\text {silica sand }}}{m_{\text {total }}} C_{\text {silica sand }}+\frac{m_{\text {basalt }}}{m_{\text {total }}} C_{\text {basalt }}+\frac{m_{\text {copper }}}{m_{\text {total }}} C_{\text {copper }}$,

where $m_{\text {silica sand }}, m_{\text {basalt }}$, and $m_{\text {copper }}$ are the selected mass $(\mathrm{kg})$ of the silica sand, basalt, and copper, respectively; $m_{\text {total }}$ is the total mass of the STES medium $(\mathrm{kg}) ; C_{\text {silica sand }}, C_{\text {basalt }}$, and $C_{\text {copper }}$ are the specific heat $\left(\mathrm{kJ} \mathrm{kg}^{-1} \mathrm{~K}^{-1}\right)$ of the STES materials silica sand, basalt, and copper, respectively.

The STES was insulated with $0.2 \mathrm{~m}$ of polyurethane foam and $0.2 \mathrm{~m}$ of concrete stratification to avoid the heat loss between the STES and the underground environment and to avoid the leakage from the surrounding groundwater as well [44].

3.5. Simulation Parameters. The simulation was constructed based on the deck file of the task 32 [5] by following the simulation running process steps inherent in TRNSYS ${ }^{\circledR}$. The simulation was performed for a five-year span starting from June where the STES can operate without an auxiliary heater. The TRNSYS $^{\circledR}$ simulation parameters are shown in Table 5.
Based on different heat demands of the buildings, the required collector area was calculated using equation (6) The collectors' tilt angles were fixed to a certain angle according to each city's coordinates. The authors did not use a solar tracking system according to its high cost, where it needs periodic maintenance as well [45]. The initial STES temperatures were equal to the ground temperatures for the three cities, respectively, where it is $21.5^{\circ} \mathrm{C}$ in Zarqa [46], $28.9^{\circ} \mathrm{C}$ in Doha [47], and $12.7^{\circ} \mathrm{C}$ in Potsdam [48].

Based on the high building's heat demand and the solid materials into the available STES volume, the temperature of the STES was set to the maximum $150^{\circ} \mathrm{C}$ for the three cities to avoid the heat dissipation and losses. Then, the collector boiling temperature was calibrated to $155^{\circ} \mathrm{C}$ [49]. The STESspecific heat was calculated using equation (8).

The rate of the covered heat demand $\left(Q_{\mathrm{HD}}\right)$ by the STES for each month will be calculated by using equation (9).

$$
\text { Covered } Q_{\mathrm{HD}}=\frac{Q_{\text {Stored }}}{Q_{\mathrm{HD}}} \times 100 \% \text {. }
$$

\section{Model Validation}

The stored thermal energy for the long term under certain climate conditions is evaluated by the capacitance of the STES to cover the building's heat demand. Therefore, the STES capacitance is the most critical metric tool that will be taken into consideration in any STES design process. TRNSYS $^{\circledR}$ simulation tool can provide an accurate illustration of the thermal performance of a STES.

In order to validate this study, another study, [16], was replicated through a TRNSYS ${ }^{\circledR}$ simulation using the same STES parameters. Accordingly, the maximum relative error for the monthly stored thermal energy between the validation and the referenced study was $1 \%$, while the average relative error was $0.6 \%$ as shown in Figure 7. 


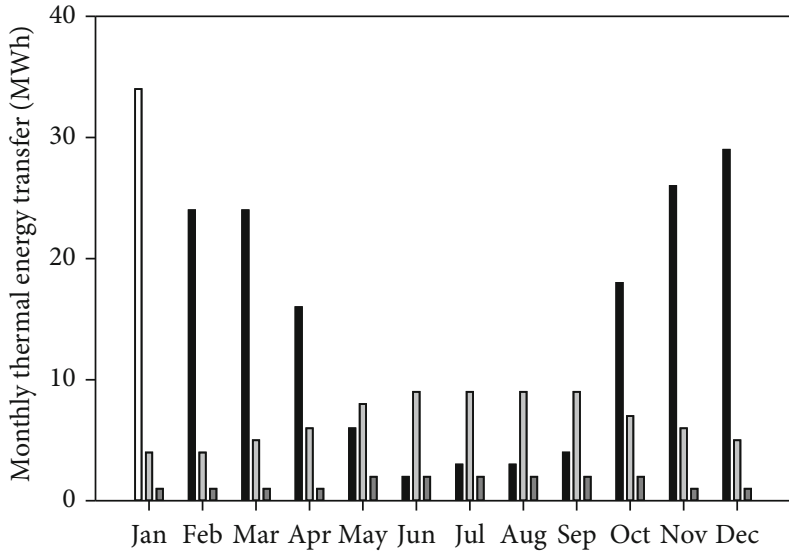

$\square Q_{\mathrm{HD}}$
$\square Q_{\text {stored }}$
$\square \mathrm{Q}_{\mathrm{L}}$

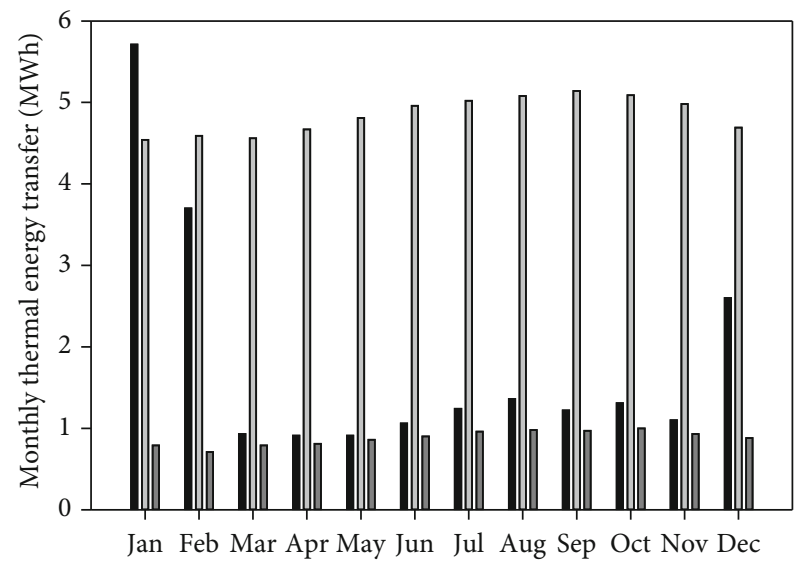
- $\mathrm{Q}_{\mathrm{HD}}$
$\square Q_{\text {stored }}$
$\square Q_{L}$

(c)

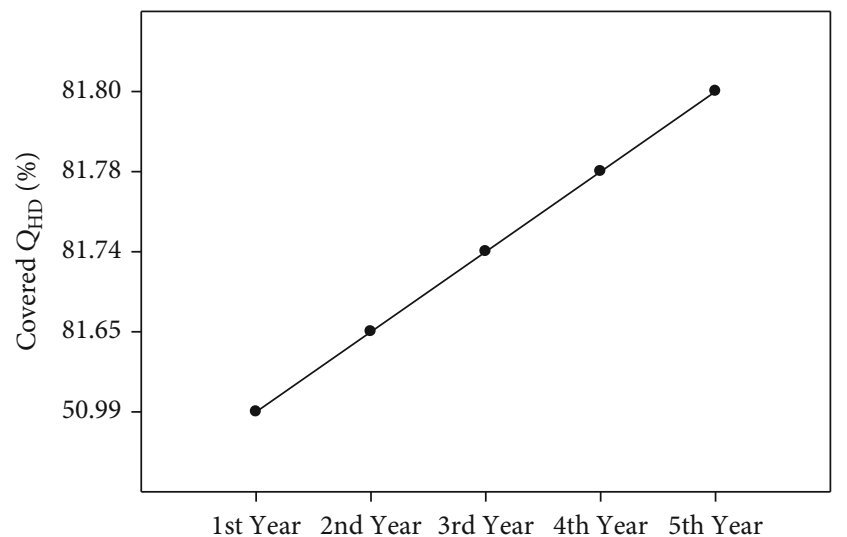

(e)

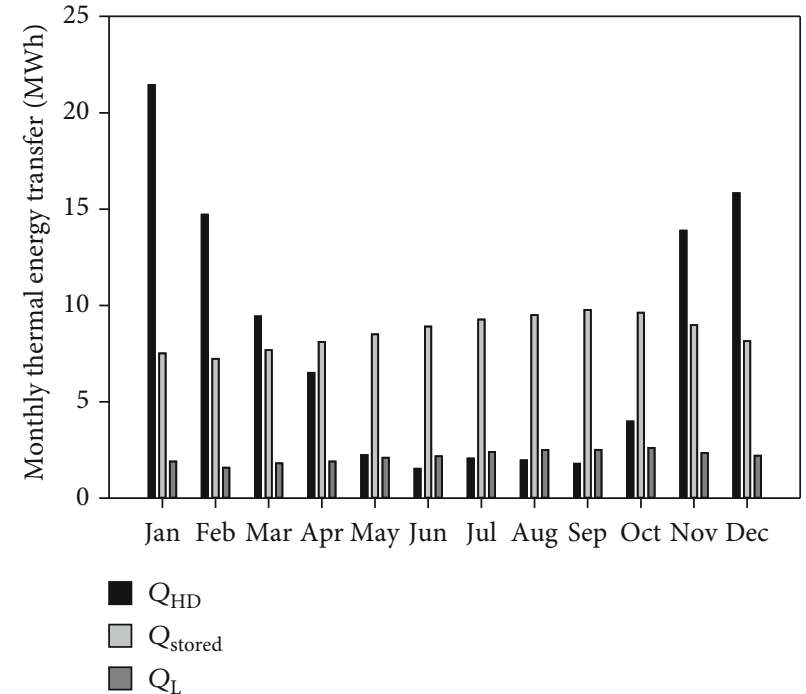

(b)

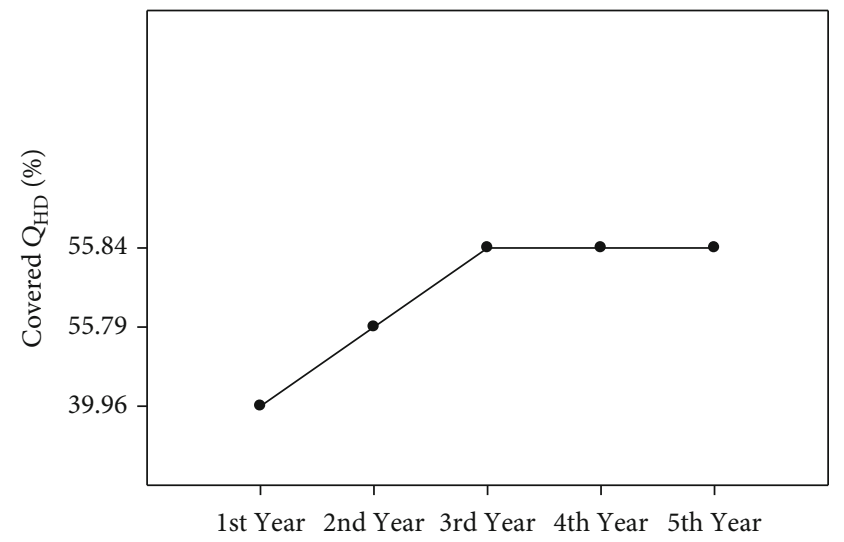

(d)

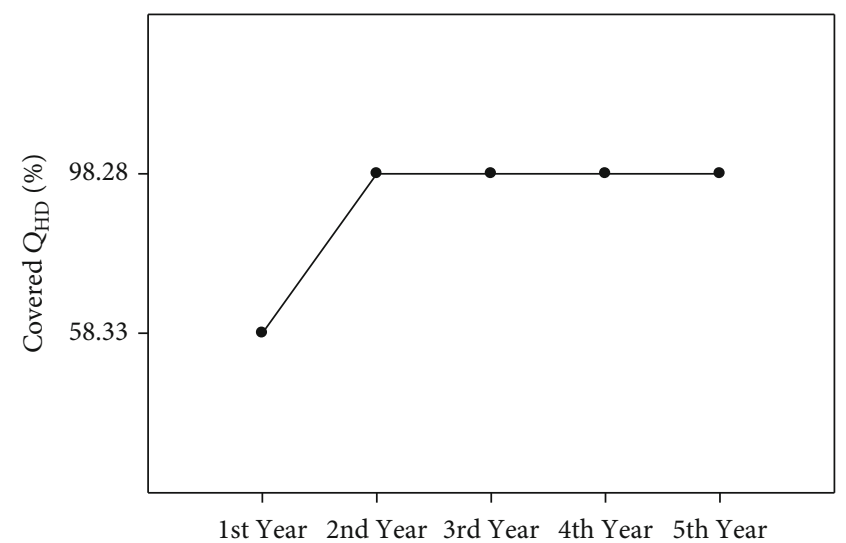

(f)

Figure 8: The TRNSYS ${ }^{\circledR}$ simulations' fifth year's STES monthly values for (a) Potsdam, (b) Zarqa, and (c) Doha. Percentage of covered heat demand (kWh) by STES during the five-year span for (d) Potsdam, (e) Zarqa, and (f) Doha. 


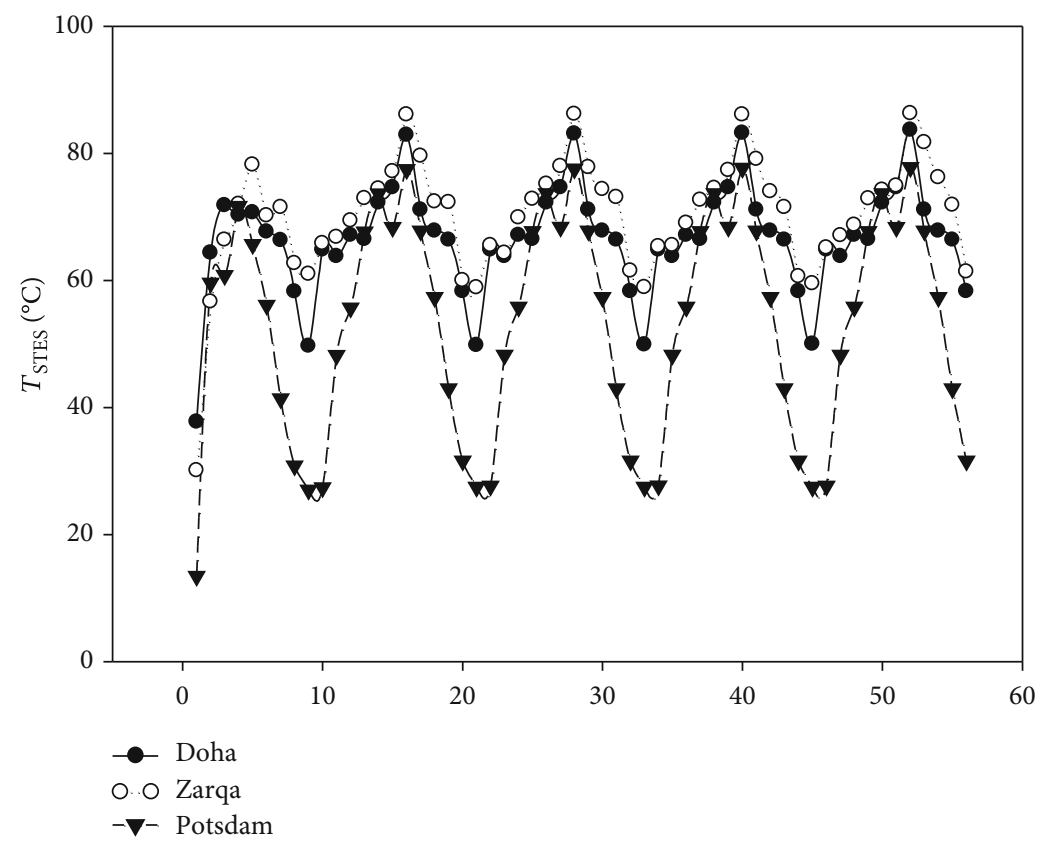

FIGURE 9: STES temperatures along the simulations' five-year span in the three selected cities.

\section{Results}

The utilization of STES allows the storage of thermal energy from the summer season to be recalled during the winter season. The design of the STES system in three different climatic zones based upon a simulation on TRNSYS ${ }^{\circledR}$ was performed, while the hotel's heat demand was calculated based on the illustrated methods and then compared with the resulted stored thermal energy from TRNSYS ${ }^{\circledR}$ simulation process. For more details about the used deck file in TRNSYS ${ }^{\circledR}$ simulation software (see Appendix (II)).

5.1. Simulation Results during the Five-Year Span for the Three Cities. The simulation results focused on the percentage of the covered hotel's heat demand where the rate of the covered heat demand $\left(Q_{\mathrm{HD}}\right)$ for each month along the fifth year of the STES operation was calculated by using equation (9).

5.1.1. The Thermal Energy Transfer in the STES. The values of the monthly TES in the STES and their relevant thermal losses throughout the whole system during the fifth year are shown in Figures 8(a)-8(c) for Potsdam, Zarqa, and Doha, respectively. For Potsdam, although the simulation was applied for five years to study the performance of the STES, the STES covered about $16 \%$ of building's heat demand in the winter months from December to February; the STES covered $100 \%$ of building's heat demand in the summer season, from June to August, as it was only necessary for the DHW load. For Zarqa, the stored thermal energy after five years of simulated operation of the STES system covered $45.23 \%$ of the building's heat demand in the winter, while it covered the whole heat demand in summer. For Doha, the simulation results after five years of STES covered the entire building's heat demand throughout the summer while it covered $36.11 \%$ in the winter.

5.1.2. The Fractions of the Covered Buildings' Heat Demand Supplied by STES. The fractions of the covered buildings' heat demand supplied by STES throughout the same five-year span are presented in Figures 8(d)-8(f) for Potsdam, Zarqa, and Doha, respectively. For Potsdam, despite using a large collectors' area, the STES was not able to cover the total heat demand of the building. The results show that the STES did not cover more than $55.84 \%$ in any of the five years of its operation, which could be attributed to the limited solar energy with low temperatures in the winter in Potsdam. Thus, cold temperatures cause a high heat loss between the building's construction envelope and the STES with their surrounding environment. The utilization of an STES system in Zarqa can provide about $81.8 \%$ of thermal energy annually due to the availability of incident solar radiation yearlong; the cumulative stored thermal energy with continuous charging can contribute to increasing the stored thermal energy throughout the STES operation process. High solar irradiance combined with high ambient temperatures in Doha allowed the STES system to provide $84.03 \%$ of the building's heat demand after the fifth year of its operation.

5.1.3. The STES Output Temperatures. Figure 9 shows the STES temperature variation along the five-year span for the three cities. The STES temperature did not drop below $57.2^{\circ} \mathrm{C}$ in the winter in Zarqa, whereas it was up to $86.1^{\circ} \mathrm{C}$ in the summer. On the other hand, the temperature reached $26.2^{\circ} \mathrm{C}$ in the winter in Potsdam, whereas it was up to $77.5^{\circ} \mathrm{C}$ in the summer season. The used collector area was $60 \mathrm{~m}^{2}$, $135 \mathrm{~m}^{2}, 250 \mathrm{~m}^{2}$ for Doha, Zarqa, and Potsdam, respectively. The STES volume was $50 \mathrm{~m}^{3}$ in Doha and was the smallest 


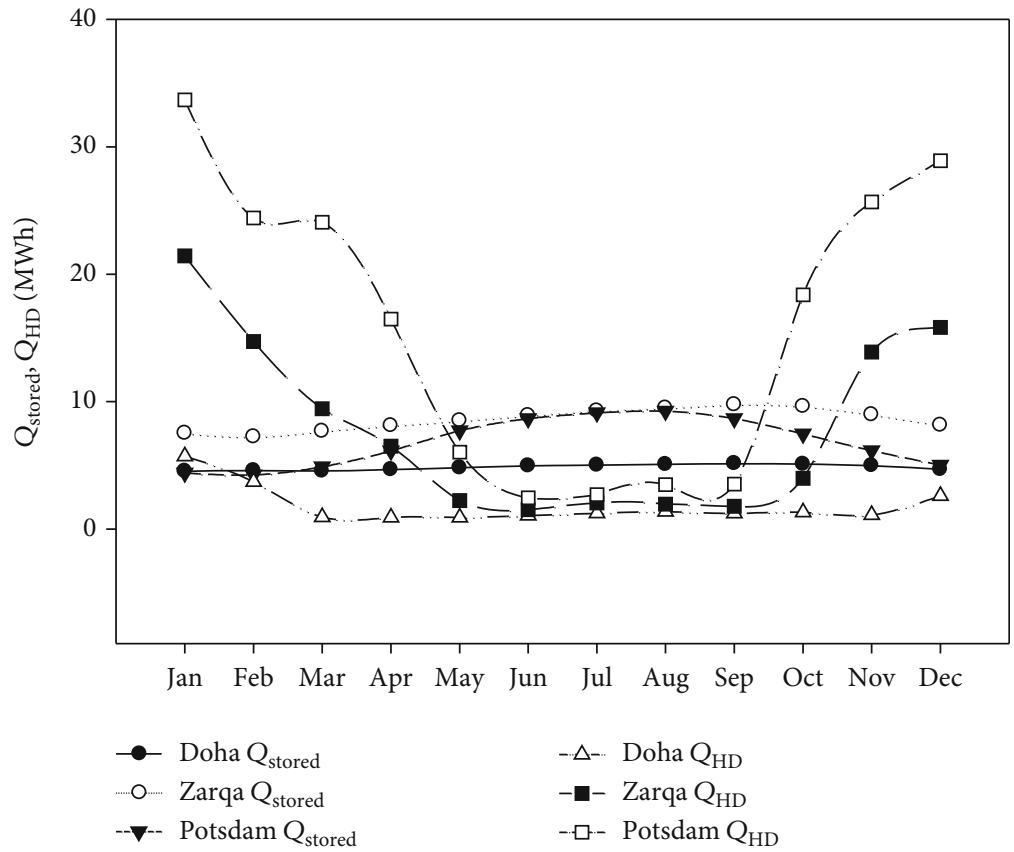

(a)

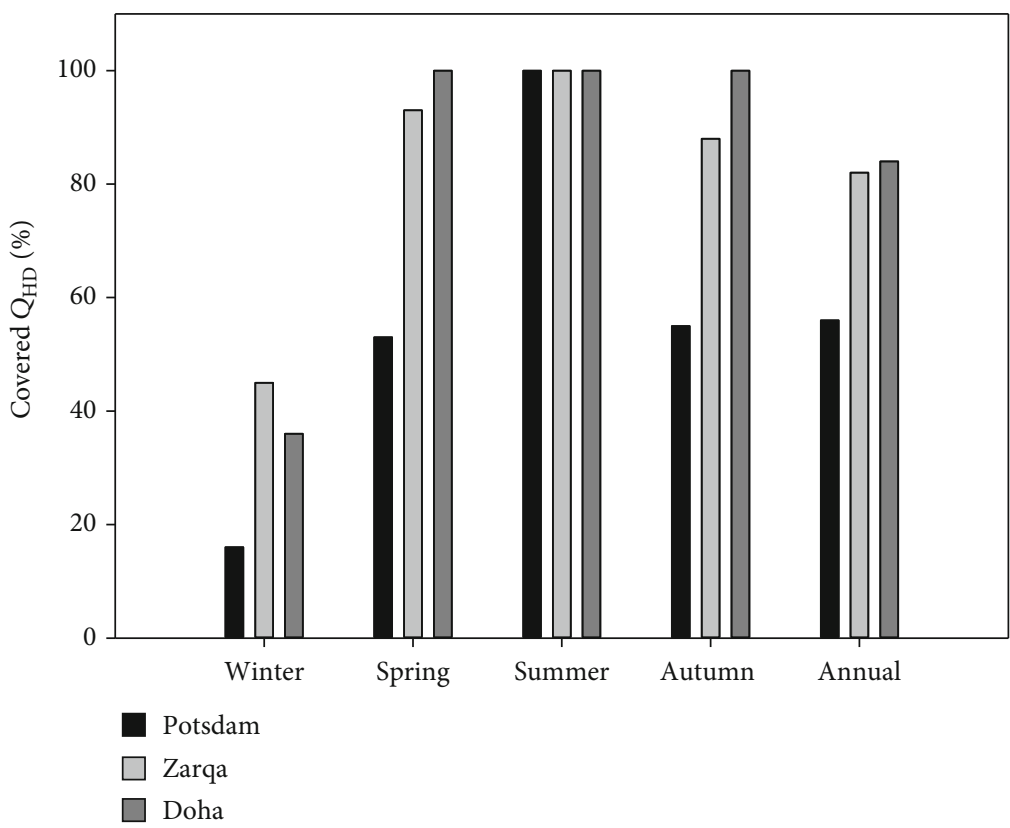

(b)

Figure 10: (a) Best results of stored solar thermal energy versus the buildings' heat demand for the three selected cities and (b) percentage of seasonal and annual covered heat demand for the same cities. 
TABLE 6: Comparison between this study and the reference used for the simulation's validation.

\begin{tabular}{|c|c|c|}
\hline & STES & STES [16] \\
\hline Excavation cost $(\$)$ & $\begin{array}{l}\text { Already buried between the building's foundations pillars } \\
\text { (There is no excavation cost) }\end{array}$ & $\begin{array}{l}\text { Buried underground beside the building (There is } \\
\text { an excavation cost) }\end{array}$ \\
\hline $\begin{array}{l}\text { Working temperature } \\
\left({ }^{\circ} \mathrm{C}\right)\end{array}$ & $\approx 1000$ & $\approx 100$ \\
\hline Corrosion & Less corrosive & Corrosive \\
\hline Freezing & Antifreezing (STES medium consists of solid materials) & It freezes below $0{ }^{\circ} \mathrm{C}$ \\
\hline Maintenance & Maintenance free & Periodic maintenance \\
\hline $\begin{array}{l}\text { STES specific heat }(\mathrm{kJ} \\
\left.\mathrm{kg}^{-1} \mathrm{~K}^{-1}\right)\end{array}$ & Low $\approx 0.77$ & High $=4.19$ \\
\hline Charge/discharge & Slow & Faster \\
\hline $\begin{array}{l}\text { STES annual capacity } \\
\left(\mathrm{kWh} \mathrm{m}^{-3}\right)\end{array}$ & (Doha: 355, Zarqa: 344, Potsdam:273) & 370 \\
\hline
\end{tabular}

TABLE 7: The capital cost of solar combisystem and STES [50].

\begin{tabular}{|c|c|c|c|c|c|}
\hline Component & Initial cost $(\$)$ & Zarqa & $\begin{array}{l}\text { Cost }(\$) \\
\text { Potsdam }\end{array}$ & Doha & Replacement period (years) \\
\hline Solar collectors & $560 \times N_{\text {collector }}+1146.8$ & 24,106 & 43,146 & 11,226 & 25 \\
\hline DTES tank & $2.746 \times V_{\text {DTES }}+952.35$ & 3,066 & 3,066 & 3,066 & 15 \\
\hline Ethylene glycol & $15.53 \times N_{\text {collector }}+148.26$ & 785 & 1,313 & 427.8 & 3 \\
\hline Pumps & 827 (each) & 1,654 & 1,654 & 1,654 & 10 \\
\hline Pipes & $5 \times 1 \mathrm{~m}$ of pipe & 200 & 200 & 200 & - \\
\hline Silica sand & $20 \times$ volume of silica sand & 1,400 & 1,400 & 400 & - \\
\hline Basalt stone & $30 \times$ volume of basalt stone & 6,000 & 6,000 & 1,050 & - \\
\hline Copper mesh & $10 \times 1 \mathrm{~m}^{2}$ of copper mesh & 10,000 & 10,000 & 2,000 & - \\
\hline Insulation (polyurethane foam) & $7 \times 1 \mathrm{~m}^{2}$ of polyurethane foam & 9,800 & 9,800 & 1,750 & - \\
\hline \multicolumn{2}{|c|}{ Total } & 57,012 & 76,580 & 21,775 & \\
\hline
\end{tabular}

$N_{\text {collector }}$ : the solar collectors' number; $V_{\text {DTES }}$ : the volume of the used DTES tank (770 liters, by applying equation (7)).

one due to the low heat demand, compared with $300 \mathrm{~m}^{3}$ in Zarqa and Potsdam. Therefore, that area of collectors in Doha was able to heat $50 \mathrm{~m}^{3}$ of STES to a maximum temperature of $84.25^{\circ} \mathrm{C}$ along five years of STES operation, while it dropped to $49.72^{\circ} \mathrm{C}$ in winter.

5.1.4. The Best Results of Stored Thermal Energy and the Covered Buildings' Heat Demand. The results of the stored thermal energy in the STES in the fifth year of simulation compared with the required building's heat demand are illustrated in Figure 10(a) along with the percentage of seasonal and annual covered heat demand simultaneously for the three cities in Figure 10(b). The stored thermal energy in Zarqa was $103,268 \mathrm{kWh}$, the highest out of three cities, due to the abundance of solar irradiance compared to Potsdam. The stored thermal energy in Potsdam at $81,800 \mathrm{kWh}$ even though that the used collector area in Potsdam was twice that in Zarqa. The results for Doha were less favorable at $17,730 \mathrm{kWh}$ due to the small collectors' area compared with Zarqa and Potsdam. The percentage of the buildings' annual covered heat demand was $81.8 \%$ for Zarqa, $55.84 \%$ for Potsdam, and $84.06 \%$ for Doha.
TABLE 8: Hotel's electricity demand cost for the three cities.

\begin{tabular}{lcccc}
\hline City & $\begin{array}{c}\text { Annual heat } \\
\text { demand } \\
(\mathrm{kWh})\end{array}$ & $\begin{array}{c}\text { Electricity } \\
\text { cost }(\$ \\
\left.\mathrm{kWh}^{-1}\right)\end{array}$ & $\begin{array}{c}\text { Electricity } \\
\text { cost } \\
\text { reference }\end{array}$ & $\begin{array}{c}\text { Annual } \\
\text { electricity cost } \\
(\$ / \mathrm{kWh})\end{array}$ \\
\hline Potsdam & 18,9737 & 0.21 & {$[51]$} & 39,845 \\
Zarqa & 94,494 & 0.13 & {$[52]$} & 15,623 \\
Doha & 22,063 & 0.04 & {$[53]$} & 883 \\
\hline
\end{tabular}

For more details, see Appendix (I) that contains the simulation results of the thermal energy transfer in the STES for the three locations.

5.2. Comparison with Literature: STES Pros and Cons. The results of this study were compared with the results of the study used for the simulation's validation in reference [16] and are listed in Table 6.

\section{Economic Evaluation}

The capital cost of the solar thermal combisystem combined with STES was calculated to be compared with electricity 


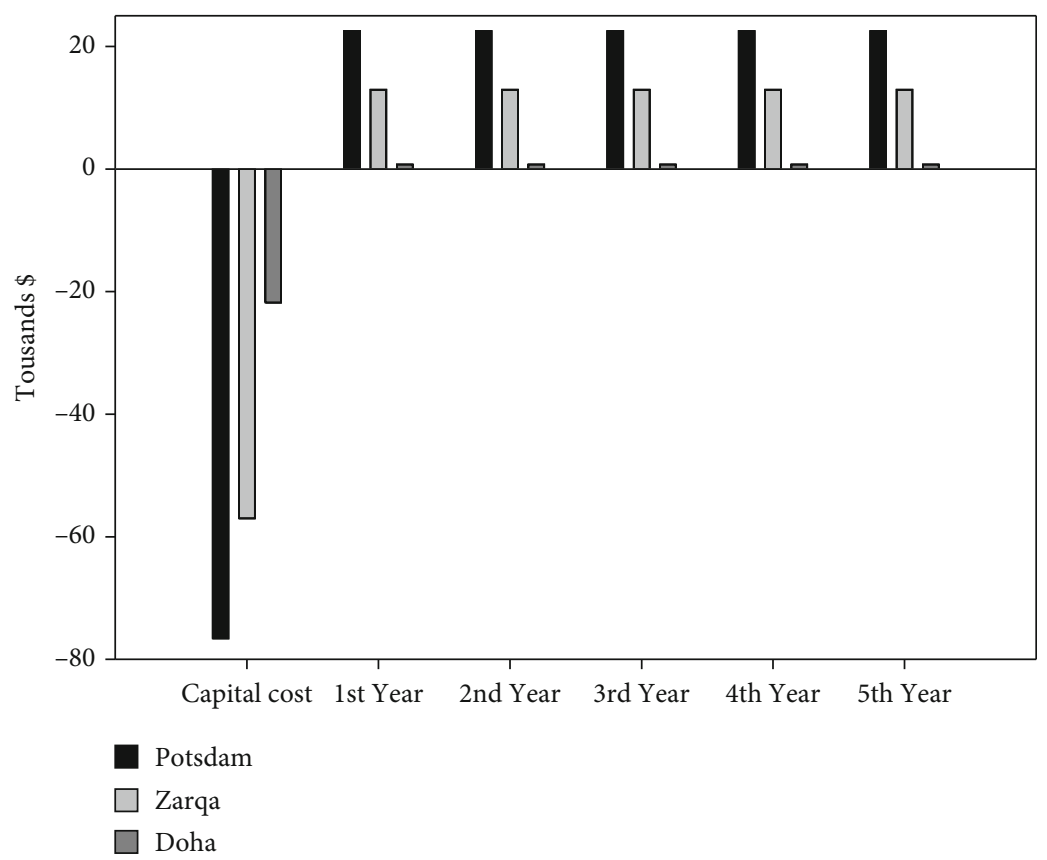

Figure 11: Cash flow diagram for the three selected locations.

consumption for covering the building's heat demand. The calculating approach of the initial cost for each component in the solar combisystem was calculated according to reference [50], while the initial cost of the STES components was calculated though best practices due to the difficulty of its pricing in the market.

6.1. The Capital Cost of the STES System for the Three Cities. The components' initial costs are listed in Table 7 for the three cities along with the replacement period of each component. The life span relevant to each component is different rendering it difficult to have a fixed life span for the whole system.

6.2. The Annual Electricity Cost and Savings for the Three Cities. The electricity consumption for covering the building's heat demand was calculated using equation (10) for the three cities in order to determine the electricity cost for each city; the results are shown in Table 8 .

$$
\begin{aligned}
& \text { Annual electricity cost }\left[\frac{\$}{\mathrm{kWh}}\right] \\
& =\text { Annual } \mathrm{HD}[\mathrm{kWh}] \times \text { Electrictiy Cost }\left[\frac{\$}{\mathrm{kWh}}\right] .
\end{aligned}
$$

The savings from the electricity bills were calculated using equation (11) for the three cities.

$$
\begin{aligned}
& \text { Annual Electricity Savings }\left[\frac{\$}{\mathrm{kWh}}\right] \\
& =Q_{\mathrm{HD}}[\mathrm{kWh}] \times \text { Covered } Q_{\mathrm{HD}} \% \times \text { Electricity Cost }\left[\frac{\$}{\mathrm{kWh}}\right] .
\end{aligned}
$$

6.3. The Cash Flow Diagram and STES System's Payback Periods for the Three Cities. Based on the calculated system's capital cost and the savings from the electricity bills for the three cities, the cash flow diagrams of the three cities were generated as shown in Figure 11.

It can be observed from Figure 11 that the net annual savings from electricity costs are around 22,533 $\$ \mathrm{kWh}^{-1}, 12,963$ $\$ \mathrm{kWh}^{-1}$, and $858 \$ \mathrm{kWh}^{-1}$ for Potsdam, Zarqa, and Doha, respectively. When the capital cost of each city, shown in Table 7, is divided by the net annual savings from electricity cost, the yield payback periods are 3.4 years, 4.4 years, and 29.4 years for Potsdam, Zarqa, and Doha, respectively.

\section{Conclusion}

All buildings are built on foundation pillars that are based deep into the ground. To increase the soil consistency between these foundation's pillars, the space is backfilled with durable basaltic materials. The underground space can be utilized for an innovative solution for a seasonal energy storage system that could be buried under the building by using the same excavation for the building's foundation, replacing regular basaltic backfill materials with solid materials that have good thermal properties. This study simulated a hotel building with $400 \mathrm{~m}^{2}$ floor area that could benefit from STES to store thermal energy during the summer and autumn seasons to take advantage of this stored energy to cover the hotel's heat demand from domestic hot water and space heating loads in the winter. The selected solid materials were silt materials that are available in the global market like silica sand and basalt stone combined with a copper mesh for heat distribution through the STES. The STES system was charged by a solar thermal combisystem for a five-year span with different collector areas in three different climate zones in Potsdam (Germany), Zarqa (Jordan), and Doha (Qatar). 
Based on the economic evaluation and the simulation of the system for the three cities, the best obtained results were for Zarqa. The system's payback period was 4.4 years combined with a coverage of $81.8 \%$ of the building's annual heat demand. The STES system covered 56\% of the building's annual heat demand in Potsdam due to the low incident solar radiation, where the system's payback period was 3.4 years. Finally, although the STES covered $84 \%$ of the building's annual heat demand in Doha, the system's payback period was 29 years due to the low price of the electricity in Qatar.

Accordingly, implementing this STES system in Zarqa would cover the building's heat demand in a feasible and efficient manner via this sustainable system.

\section{Appendix}

\section{A. The best results of the stored thermal energy in the fifth year compared with the hotel's heat demand for the three cities.}

\begin{tabular}{|c|c|c|c|c|}
\hline \multirow{2}{*}{ Months } & \multicolumn{4}{|c|}{ Potsdam } \\
\hline & $Q_{\text {STES }}(\mathrm{kWh})$ & $Q_{\mathrm{HD}}(\mathrm{kWh})$ & $Q_{\mathrm{L}}(\mathrm{kWh})$ & Covered $Q_{\mathrm{HD}} \%$ \\
\hline Jan & 4,396 & 33,679 & 793 & $13.05 \%$ \\
\hline Feb & 4,252 & 24,406 & 611 & $17.42 \%$ \\
\hline Mar & 4,891 & 24,068 & 736 & $20.32 \%$ \\
\hline Apr & 6,144 & 16,470 & 1,075 & $37.30 \%$ \\
\hline May & 7,722 & 6,027 & 1,516 & $100 \%$ \\
\hline Jun & 8,680 & 2,454 & 1,963 & $100 \%$ \\
\hline Jul & 9,128 & 2,686 & 2,337 & $100 \%$ \\
\hline Aug & 9,263 & 3,477 & 2,412 & $100 \%$ \\
\hline Sep & 8,674 & 3,521 & 2,213 & $100 \%$ \\
\hline Oct & 7,470 & 18,371 & 1,971 & $40.66 \%$ \\
\hline Nov & 6,164 & 25,666 & 1,437 & $24.02 \%$ \\
\hline Dec & 5,017 & 28,912 & 1,085 & $17.35 \%$ \\
\hline Total & 81,800 & 189,737 & 18,148 & - \\
\hline Avg & 6,817 & 15,811 & 1,512 & $55.84 \%$ \\
\hline \multirow{2}{*}{ Months } & \multicolumn{4}{|c|}{ Zarqa } \\
\hline & $Q_{\text {STES }}(\mathrm{kWh})$ & $Q_{\mathrm{HD}}(\mathrm{kWh})$ & $Q_{\mathrm{L}}(\mathrm{kWh})$ & Covered $Q_{\mathrm{HD}} \%$ \\
\hline Jan & 7,523 & 21,436 & 1,898 & $35.10 \%$ \\
\hline Feb & 7,235 & 14,721 & 1,566 & $49.15 \%$ \\
\hline Mar & 7,679 & 9,441 & 1,799 & $81.34 \%$ \\
\hline Apr & 8,111 & 6,508 & 1,897 & $100 \%$ \\
\hline May & 8,504 & 2,231 & 2,092 & $100 \%$ \\
\hline Jun & 8,907 & 1,518 & 2,169 & $100 \%$ \\
\hline Jul & 9,274 & 2,053 & 2,386 & $100 \%$ \\
\hline Aug & 9,505 & 1,959 & 2,489 & $100 \%$ \\
\hline Sep & 9,774 & 1,783 & 2,495 & $100 \%$ \\
\hline Oct & 9,632 & 3,982 & 2,601 & $100 \%$ \\
\hline Nov & 8,978 & 13,893 & 2,342 & $64.63 \%$ \\
\hline Dec & 8,146 & 15,834 & 2,201 & $51.44 \%$ \\
\hline Total & 103,268 & 94,494 & 25,935 & - \\
\hline Avg & 8,606 & 7,947 & 2,161 & $81.80 \%$ \\
\hline
\end{tabular}

TABLE: Continued.

\begin{tabular}{lcccc}
\hline \multirow{2}{*}{ Months } & \multicolumn{4}{c}{ Doha } \\
& $Q_{\text {STES }}(\mathrm{kWh})$ & $Q_{\mathrm{HD}}(\mathrm{kWh})$ & $Q_{\mathrm{L}}(\mathrm{kWh})$ & Covered $Q_{\mathrm{HD}} \%$ \\
\hline Jan & 1,254 & 5,715 & 484 & $21.95 \%$ \\
Feb & 1,362 & 3,702 & 468 & $36.78 \%$ \\
Mar & 1,358 & 931 & 543 & $100 \%$ \\
Apr & 1,431 & 913 & 591 & $100 \%$ \\
May & 1,516 & 910 & 635 & $100 \%$ \\
Jun & 1,592 & 1,057 & 674 & $100 \%$ \\
Jul & 1,581 & 1,240 & 713 & $100 \%$ \\
Aug & 1,602 & 1,362 & 721 & $100 \%$ \\
Sep & 1,643 & 1,220 & 710 & $100 \%$ \\
Oct & 1,592 & 1,315 & 722 & $100 \%$ \\
Nov & 1,509 & 1,096 & 652 & $100 \%$ \\
Dec & 1,290 & 2,602 & 580 & $49.59 \%$ \\
Total & 17,730 & 22,063 & 7,492 & - \\
Avg & 1,477 & 1,839 & 624 & $84.03 \%$
\end{tabular}

\section{Data Availability}

All data are included in the manuscript.

\section{Conflicts of Interest}

The authors declare that they have no conflicts of interest.

\section{References}

[1] G. Hailu, "Seasonal solar thermal energy storage," in Thermal Energy Battery with Nano-enhanced PCM, M. S. Kandelousi, Ed., IntechOpen, 2018.

[2] C. Spandagos and T. L. Ng, "Equivalent full-load hours for assessing climate change impact on building cooling and heating energy consumption in large Asian cities," Applied Energy, vol. 189, pp. 352-368, 2017.

[3] D. P. M. Meena and M. Choudhary, "Thermal energy storage in sensible materials: a review," INTERNATIONAL JOURNAL OF ADVANCE RESEARCH, IDEAS AND INNOVATIONS IN TECHNOLOGY, vol. 3, pp. 607-613, 2017.

[4] L. Gao, J. Zhao, and Z. Tang, "A review on borehole seasonal solar thermal energy storage," Energy procedia, vol. 70, pp. 209-218, 2015.

[5] R. Heimrath and M. Haller, The Reference Heating System, the Template Solar System of task 32-Report A2 of Subtask A, Graz, Austria, 2007.

[6] M. L. Sweet and J. T. McLeskey, "Numerical simulation of underground Seasonal Solar Thermal Energy Storage (SSTES) for a single family dwelling using TRNSYS," Solar Energy, vol. 86, no. 1, pp. 289-300, 2012.

[7] L. T. Terziotti, M. L. Sweet, and J. T. McLeskey Jr., "Modeling seasonal solar thermal energy storage in a large urban residential building using TRNSYS 16," Energy and Buildings, vol. 45, pp. 28-31, 2012.

[8] N. Al-sudany, A. Al-Sa'ady, F. Al-bahadly, and A. Al-sudany, "The seasonal storage of thermal solar energy in Iraq," International Journal of Application or Innovation in Engineering \& Management, vol. 3, pp. 77-85, 2014. 
[9] J. Milewski, M. Wołowicz, and W. Bujalski, "Seasonal thermal energy storage - a size selection," Applied Mechanics and Materials, vol. 467, pp. 270-276, 2014.

[10] C. N. Antoniadis and G. Martinopoulos, "Simulation of solar thermal systems with seasonal storage operation for residential scale applications," Procedia Environmental Sciences, vol. 38, pp. 405-412, 2017.

[11] G. Hailu, P. Hayes, and M. Masteller, "Seasonal solar thermal energy sand-bed storage in a region with extended freezing periods: Part I experimental investigation," Energies, vol. 10, no. 11, p. 1873, 2017.

[12] M. Diago, A. C. Iniesta, A. Soum-Glaude, and N. Calvet, "Characterization of desert sand to be used as a high-temperature thermal energy storage medium in particle solar receiver technology," Applied Energy, vol. 216, pp. 402-413, 2018.

[13] Z. Ma, H. Bao, and A. P. Roskilly, "Feasibility study of seasonal solar thermal energy storage in domestic dwellings in the UK," Solar Energy, vol. 162, pp. 489-499, 2018.

[14] S. Kiwan and Q. R. Soud, "Numerical investigation of sandbasalt heat storage system for beam-down solar concentrators," Case Studies in Thermal Engineering, vol. 13, article 100372, 2019.

[15] H. Gunerhan and A. Hepbasli, "Utilization of basalt stone as a sensible heat storage material," Energy Sources, vol. 27, no. 14, pp. 1357-1366, 2005.

[16] I. Beausoleil-Morrison, B. Kemery, A. D. Wills, and C. Meister, "Design and simulated performance of a solar-thermal system employing seasonal storage for providing the majority of space heating and domestic hot water heating needs to a singlefamily house in a cold climate," Solar Energy, vol. 191, pp. 57-69, 2019.

[17] J. Lu, G. He, and F. Mao, "Solar seasonal thermal energy storage for space heating in residential buildings: optimization and comparison with an air-source heat pump," Policy, vol. 15, no. 5, pp. 279-296, 2020.

[18] I. Stadler, "The three pillars for a $100 \%$ energy supply with renewable energies," uwf UmweltWirtschaftsForum, vol. 22, no. 1, pp. 17-27, 2014.

[19] "National Climatic Data Center (NCDC) Search | Climate Data Online (CDO) | National Climatic Data Center (NCDC)," https://www.ncdc.noaa.gov/cdo-web/search.

[20] "Photovoltaic Geographical Information System (PVGIS) JRC Photovoltaic Geographical Information System (PVGIS) European Commission," https://www.ncdc.noaa.govhttps//re .jrc.ec.europa.eu/pvg_tools/en/tools.html\#/cdo-web/search.

[21] A. M. Baniyounes, "Renewable energy potential in Jordan," International Journal of Applied Engineering Research, vol. 12, pp. 8323-8331, 2017.

[22] "Global Solar Atlas (GSA) Global Solar Atlas Datavol. 3https:// globalsolaratlas.info/map?c=11.523088.

[23] A. Alkhalidi, S. Kiwan, and H. Hamasha, "A comparative study between Jordanian overall heat transfer coefficient (Uvalue) and international building codes," in 2019 10th International Renewable Energy Congress (IREC), pp. 1-5, Sousse, Tunisia, 2019.

[24] D.-N. I. Daas, "National Technical Committee for Preparing and Development-Concrete Structures Requirements," 2014.

[25] I. Al-Hinti and H. Al-Sallami, "Potentials and barriers of energy saving in Jordan's residential sector through thermal insulation," Jordan Journal of Mechanical \& Industrial Engineering, vol. 11, pp. 141-145, 2017.
[26] E. Sonderveröffentlichung and D. Hotelbau, "Hotel's energy demand in Germany," https://www.facility-manager.de/.

[27] M. Khalfan, S. Sharples, A. Alexander, C. Skelhorn, and J. A. Bryant, "The first Passivhaus in Qatar: initial monitoring and modelling energy performance," 2014.

[28] "Standard Assessment Procedure (SAP) The Government's Standard Assessment Procedure for Energy Rating of Dwellings in UK," https://www.bre.co.uk/filelibrary/SAP/2012/ SAP-2012_9-92.pdf.

[29] M. Richard, Simulating Domestic Hot Water Demand by means of a Stochastic End-Use Model, Stellenbosch University, 2016.

[30] A. Sakhrieh and A. Al-ghandoor, "Experimental investigation of the performance of five types of solar collectors," Energy Conversion and Management, vol. 65, pp. 715-720, 2013.

[31] A. Maraj, A. Londo, C. Firat, and A. Gebremedhin, "Comparison of the energy performance between flat-plate and heat pipe evacuated tube collectors for solar water heating systems under Mediterranean climate conditions," Journal of Sustainable Development of Energy, Water and Environment Systems, vol. 7, no. 1, pp. 87-100, 2019.

[32] D.-M. Viessmann, "Technical guide - solar thermal sysetms," https://www.viessmann.be/.

[33] S. Co, "Ltd Solar Systems - Evacuated tubes \& Flat plate collectors' specifications," vol. 49, 2016.

[34] J. A. Duffie and W. A. Beckman, Solar Engineering of Thermal Processes Book, Research supported by the University of Wisconsin, New York, 2006, Fourth Edi..

[35] J. S. LaKind, E. A. McKenna, R. P. Hubner, and R. G. Tardiff, "A review of the comparative mammalian toxicity of ethylene glycol and propylene glycol," Critical Reviews in Toxicology, vol. 29, no. 4, pp. 331-365, 1999.

[36] W. Weiss, "Design of solar thermal design of solar thermal systems - calculation methods," http://www.crses.sun.ac.za/files/ services/events/workshops/03_Design\%20ST\%20Systems_ Calculation\%20methods.pdf.

[37] P. D.-I. P. Stephan, VDI Heat Atlas - standard book for heat exchanger, P. D.-I. P. Stephan and P.-I. Martin, Eds., Springer, Second Edition edition, 2010.

[38] N. Mehyar, M. Madanat, and J. Sahawneh, "Mineral status and future opportunity (Basalt)," http://www.memr.gov.jo/ EchoBusV3.0/SystemAssets/PDFs/AR/MineralTR/Basalt.pdf.

[39] P.-S. A. Taqieddin, "Physical and engineering properties of some selected Jordanian basalt," http://www.ijier.net/.

[40] M. Diago, A. C. Iniesta, T. Delclos, T. Shamim, and N. Calvet, "Characterization of desert sand for its feasible use as thermal energy storage medium,” Energy Procedia, vol. 75, pp. 21132118, 2015.

[41] E. C. E. Rönnebro, G. Whyatt, M. Powell, M. Westman, F. Zheng, and Z. Z. Fang, "Metal hydrides for hightemperature power generation," Energies (Basel), vol. 8, no. 8, pp. 8406-8430, 2015.

[42] "AZo materials silica - silicon dioxide ( $\mathrm{SiO} 2)$ ".

[43] "AZo materials copper - specifications, properties, classifications and classes".

[44] G. Hailu, P. Hayes, and M. Masteller, "Long-term monitoring of sensible thermal storage in an extremely cold region," Energies (Basel), vol. 12, no. 9, p. 1821, 2019.

[45] M. Z. Jacobson and V. Jadhav, "World estimates of PV optimal tilt angles and ratios of sunlight incident upon tilted and 
tracked PV panels relative to horizontal panels," Solar Energy, vol. 169, pp. 55-66, 2018.

[46] I. Al-Hinti, A. Al-Muhtady, and W. Al-Kouz, "Measurement and modelling of the ground temperature profile in Zarqa, Jordan for geothermal heat pump applications," Applied Thermal Engineering, vol. 123, pp. 131-137, 2017.

[47] L. U. Xing, Estimations of undisturbed ground temperatures using numerical and analytical modeling (Doctoral dissertation, Oklahoma State University), 2014.

[48] "Potsdam Institute for Climate Impact Research (PIK) Ground temperature - PIK Research," https://www.pik-potsdam.de/ services/climate-weather-potsdam/climate-diagrams/groundtemperature/index_html?set_language=en.

[49] R. Hausner and C. Fink, Stagnation behaviour of solar thermal systems - task 26, Gleisdorf, Feldgasse 19 Austria, 2002.

[50] J. N. C. Hin and R. Zmeureanu, "Optimization of a residential solar combi-system for minimum life cycle energy and cost," in Proceedings of eSim 2012: The Canadian Conference on Building Simulation, pp. 94-107, Concordia University, 2012.

[51] "Clean Energy Wire (CEW) German power cost | Journalism for the energy transition," https://www.cleanenergywire.org/ factsheets/what-german-households-pay-power.

[52] "Nationl Electric Power Company (NEPCO) Nationl Electric Power Company - NEPCO," http://www.nepco.com.jo/en/ electricity_tariff_en.aspx.

[53] "Qatar General Electricity \& water Corporation (QGEWC) Qatar General Electricity \& water Corporation," https://www .km.qa/Pages/default.aspx. 